\title{
COMPOSITION EFFECTS ON SHEEN AND SPREAD RATE OF AN INTERIOR FLAT, ONE COAT LATEX PAINT FORMULATION
}

\author{
A Project Report \\ presented to \\ the Faculty of California Polytechnic State University, \\ San Luis Obispo
}

In Partial Fulfillment of the Requirements for the Degree Master of Science in Polymers and Coatings

Dana James Christensen II

August 2015 
(C) 2015

Dana James Christensen II

ALL RIGHTS RESERVED 
TITLE:

AUTHOR:

DATE SUBMITTED:

COMMITTEE CHAIR:

COMMITTEE MEMBER:

COMMITTEE MEMBER:
Composition Effects on Sheen and Spread Rate of an Interior Flat, One Coat Latex Paint Formulation

Dana James Christensen II

August 2015

Raymond H. Fernando, Ph.D.

Professor of Chemistry

Michael P. Diebold, Ph.D.

Research Fellow, The Chemours ${ }^{\mathrm{TM}}$ Company

Philip J. Costanzo, Ph.D.

Associate Professor of Chemistry 


\begin{abstract}
Composition Effects on Sheen and Spread Rate of an Interior Flat, One Coat Latex Paint

Formulation

Dana James Christensen II
\end{abstract}

Interior flat, white latex paint is a common coating applied to walls around the world. Development of a coating with one coat hide capability is a pinnacle achievement for paint formulators as it has the potential to save consumers both time and money. One coat paints already exist on the market, but they are limited in color, coverage, and often have many disclaimers. Work done was part of a project initiated by Chemours ${ }^{\mathrm{TM}}$ Titanium Technologies.

The goal of the project presented in this article was to create an interior flat, white latex paint that yields a spread rate of greater than $400 \mathrm{ft}^{2} /$ gal., which is advertised by many below critical pigment volume concentration (CPVC) commercial paints. In order to achieve this goal, an above CPVC paint with a high $\mathrm{TiO}_{2}$ content was created and continuously improved. Improvement of the formulation involved numerous experimental variations including adjustments to the hydroxyethylcellulose (HEC) molecular weight, dispersant chemistry, latex chemistry, $\mathrm{TiO}_{2}$ concentration, extender package, and rheology modifier type. The sheen value, relative light scattering, and spread rate were the main measurements conducted in order to judge formulation improvement.

Complications with the spread rate procedure forced its adaptation in order to collect less variable data with the high density, shear thinning formulations. It was found 
that shorter opacity charts yielded more precise spread rate data than the longer opacity charts. An attempt at correlating rheology with sheen development resulted in the conclusion that the pigment and extender particle package is the greatest driving factor behind sheen reduction. The rheology modifier type and dispersant chemistry did not affect the flatness of the paint nearly as much. A Keyence VR-3000 series One-Shot 3D Measuring Macroscope was used to show that surface roughness does not directly correlate to the sheen value when a number of flat paints with different sheens were analyzed.

This project is an ongoing effort and the information contained in this document will substantially help future development.

Keywords: titanium dioxide, light scattering, spread rate, contrast ratio, critical pigment volume concentration (CPVC), one coat, sheen, interior flat paint, surface roughness 


\section{ACKNOWLEDGMENTS}

I would like to thank The Chemours Company, particularly Dr. Michael Diebold and Dr. Nathaniel Barney, for the opportunity and their guidance along the way. The experience that I gained by working with them and the rest of the Chemours Titanium Technology team was truly life-changing. I thank Dr. Raymond Fernando for his outstanding advisement as I would not be where I am today without his guidance. I would also like to thank Dr. Philip Costanzo for his support during my time in the Polymers and Coatings Program. A special thanks to the Cal Poly Bill Moore Fellowship Fund and the Los Angeles Society for Coatings and Technology (LASCT) for their financial backing. 


\section{TABLE OF CONTENTS}

Page

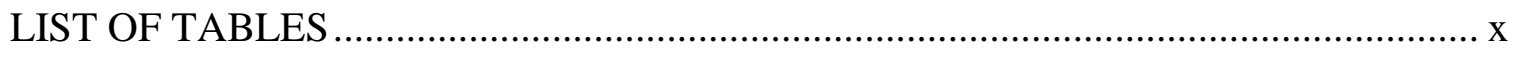

LIST OF FIGURES ...................................................................................

\section{CHAPTER}

1. INTRODUCTION ....................................................................................... 1

1.1 One Coat Interior Architectural Paint ..................................................... 1

1.2 Paint Components ................................................................................ 1

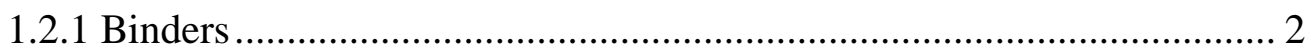

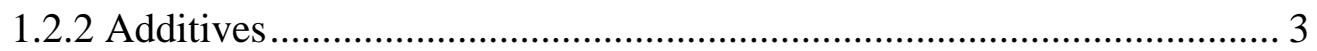

1.2.2.1 Rheology Modifiers ...................................................... 3

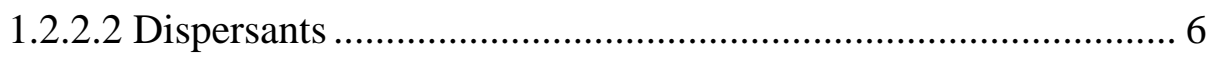

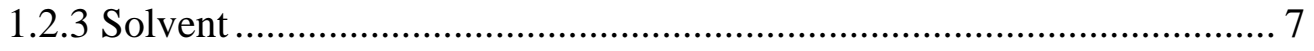

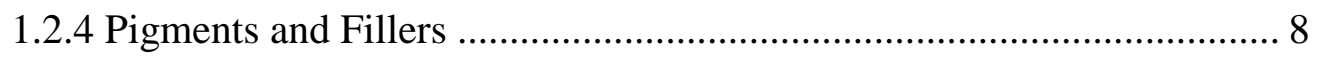

1.3 Pigment Volume Concentration ............................................................ 9

1.3.1 Oil Absorption .................................................................. 10

1.3.2 Gloss ................................................................................ 10

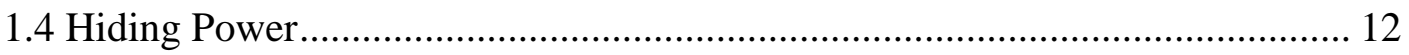

1.4.1 Contrast Ratio ........................................................................ 13

1.5 Titanium Dioxide ................................................................................... 14

1.5.1 Production Methods ................................................................ 14

1.5.2 Pigment Grades .................................................................. 15

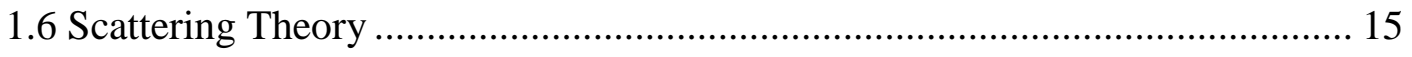

1.6.1 Particle Size ........................................................................ 16 


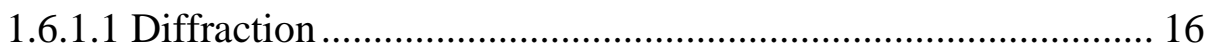

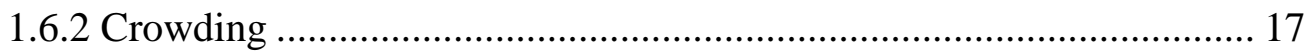

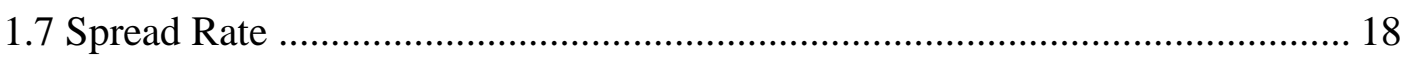

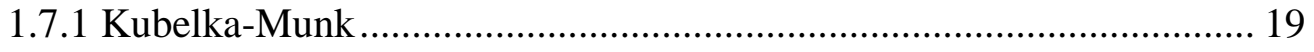

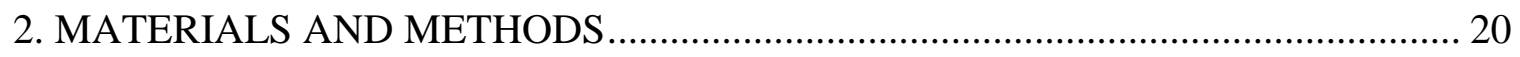

2.1 Spread Rate Procedure …………………………...................................... 20

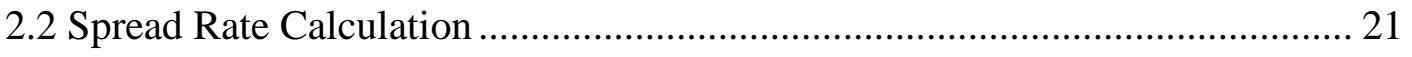

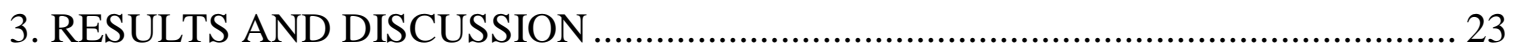

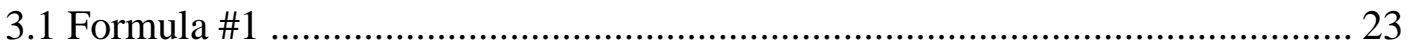

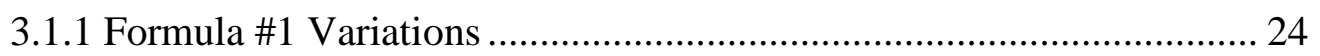

3.1.2 HEC Molecular Weight ................................................................ 26

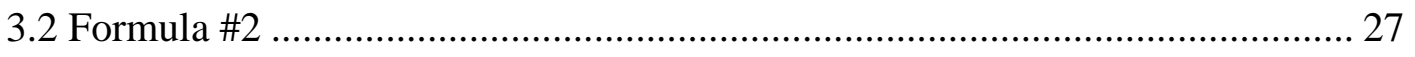

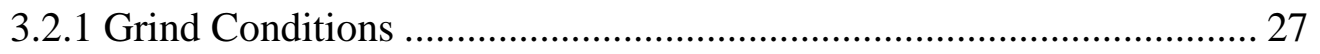

3.2.2 Dispersant Chemistry ...................................................................... 29

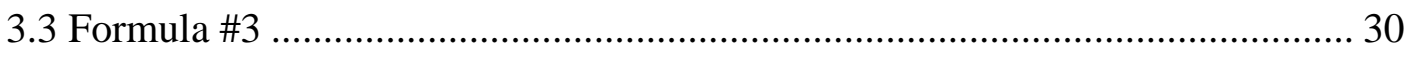

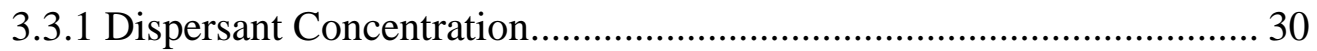

3.3.2 Pigment and Dispersant Combinations................................................ 31

3.3.3 Formula \#3 Variability .................................................................... 33

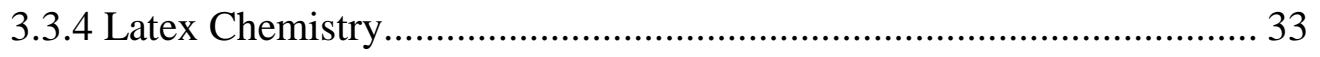

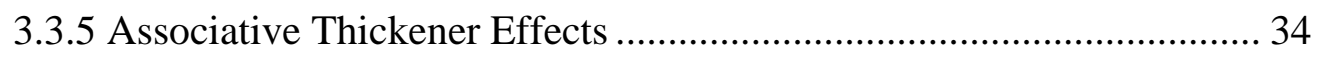

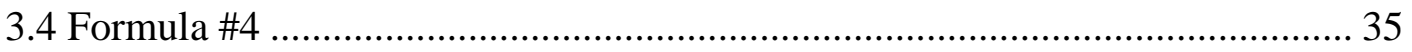

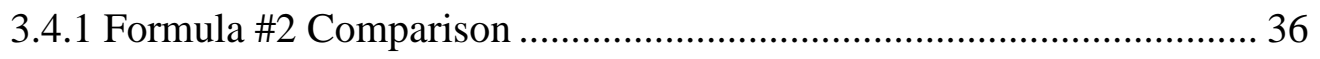

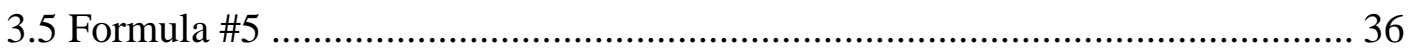


3.5.1 Formula \#4 Comparison

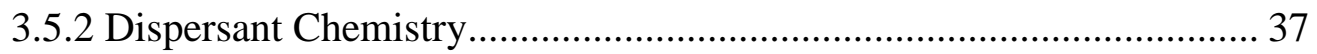

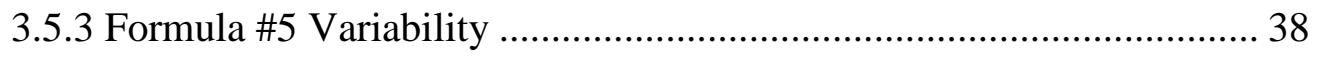

3.6 Spread Rate Method Variability ............................................................... 40

3.6.1 Chart Comparison ................................................................ 41

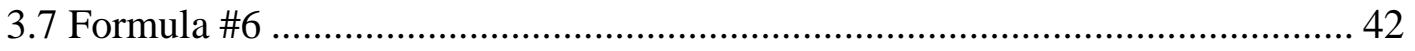

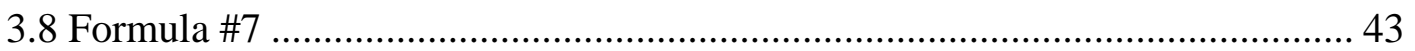

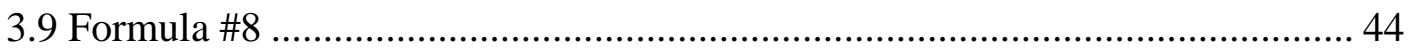

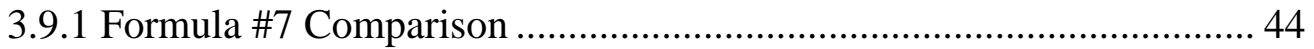

3.9.2 Rheology Modifier Chemistry ….............................................. 45

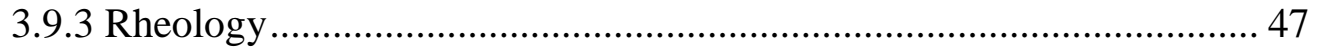

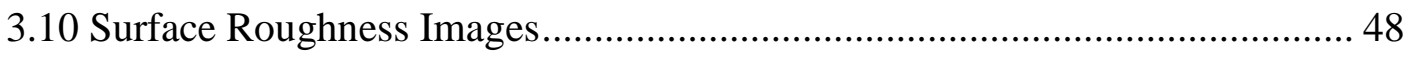

3.10.1 Film Formation .............................................................. 48

3.10.2 Commercial Paint Comparison ................................................... 52

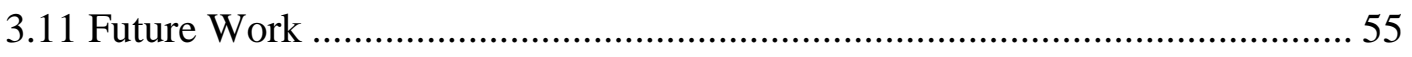

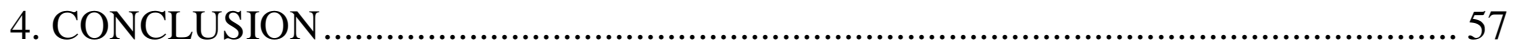

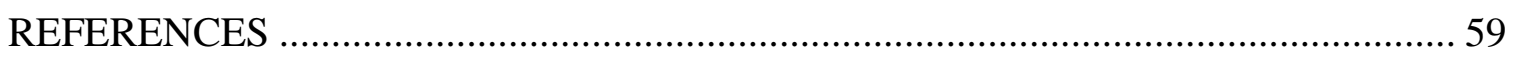

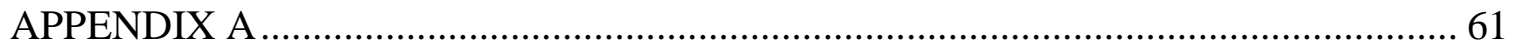




\section{LIST OF TABLES}

Table

Page

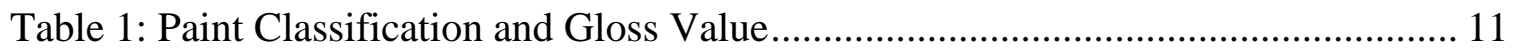

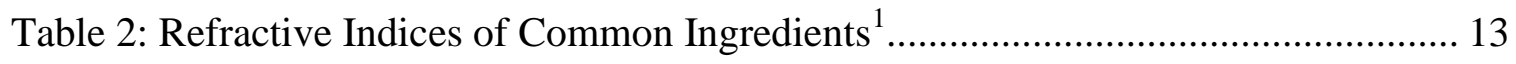

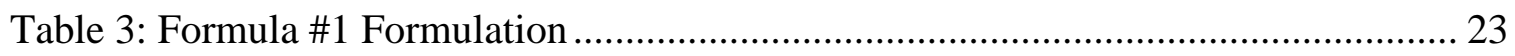

Table 4: First Trial Data for Formulation \#1 _........................................................... 24

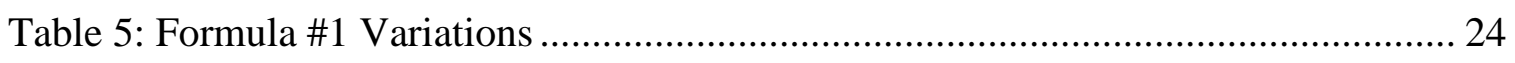

Table 6: Data for Formula \#1 Variations ..................................................................... 24

Table 7: HEC Thickener Molecular Weights ............................................................ 26

Table 8: Data for Formula \#1 HEC Variations ........................................................ 26

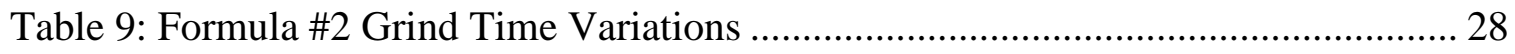

Table 10: Data for Formula \#2 Grind Time Variations ............................................. 28

Table 11: Data for Formula \#2 Dispersant Variations ............................................... 29

Table 12: Formula \#3 Dispersant Concentration Variations ........................................ 30

Table 13: Data for Formula \#3 Dispersant Concentration Variations ............................. 31

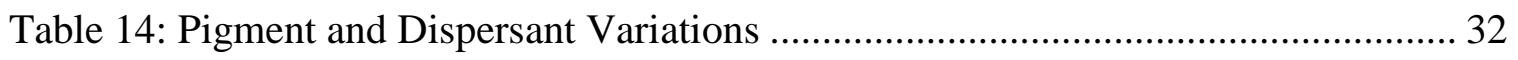

Table 15: Data for Pigment and Dispersant Variations ............................................ 32

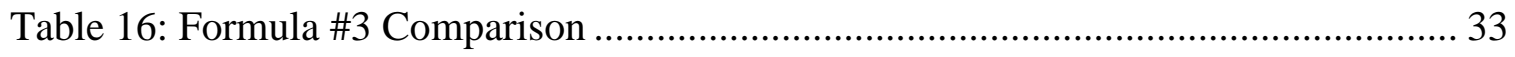

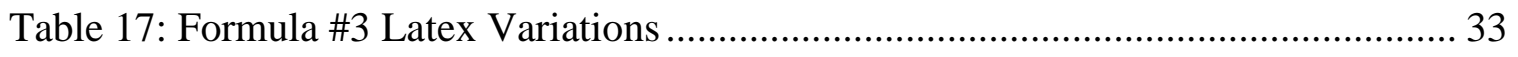

Table 18: Data for Formula \#3 Latex Variations ........................................................ 34

Table 19: Data for Latex B With and Without Associative Thickener........................... 34

Table 20: Data for Latex C With and Without Associative Thickener........................... 35

Table 21: Data for Latex D With and Without Associative Thickener .......................... 35

Table 22: Data for Formula \#4 Comparison .............................................................. 36 
Table 23: Data for Formula \#5 Comparison ............................................................... 37

Table 24: Averaged Data for Formula \#5 Dispersant Variation Triplicates .................... 37

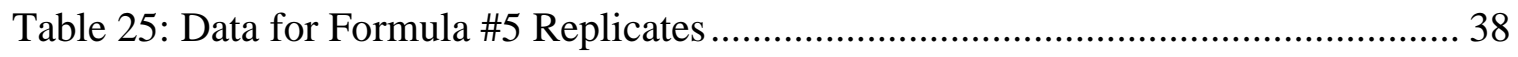

Table 26: Data for Formula \#5 Collected on Second Vacuum Plate ............................... 39

Table 27: Formula \#5 Data Showing Chart Variability ............................................ 40

Table 28: Formula \#5 Long vs. Short Opacity Chart.................................................. 41

Table 29: Spread Rate Precision on Short Opacity Chart........................................... 42

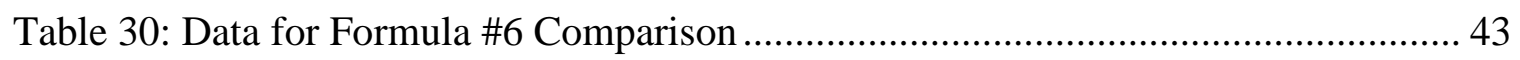

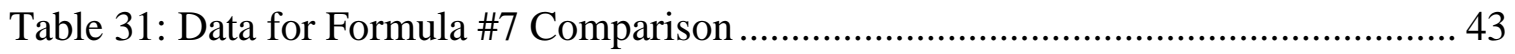

Table 32: Data for Formula \#8 Comparison ............................................................ 44

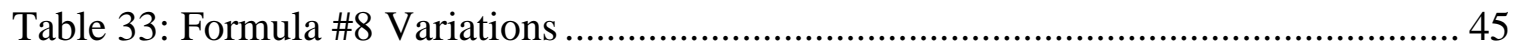

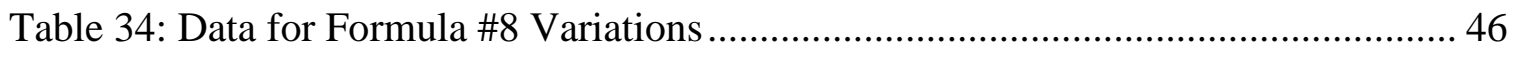

Table 35: Surface Roughness Data for Formula \#8 Film Formation ............................ 50

Table 36: Surface Roughness Parameter Descriptions .............................................. 50

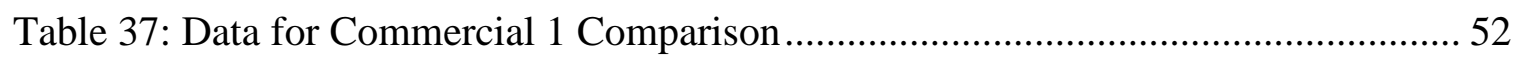

Table 38: Surface Roughness Data for Comparison ................................................ 54 


\section{LIST OF FIGURES}

Figure Page

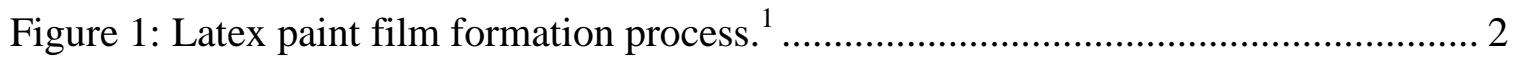

Figure 2: General structure of cellulosic thickeners. ............................................. 4

Figure 3: General structure of a HEUR thickener. ..................................................... 5

Figure 4: General structure of a HASE thickener..................................................... 5

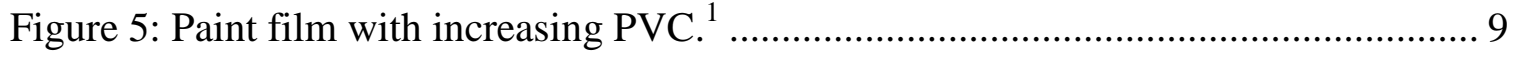

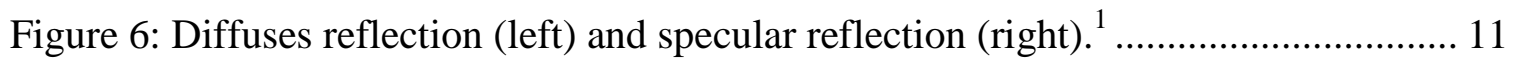

Figure 7: Reflectance of $\mathrm{TiO}_{2}$ pigment in various regions of the spectrum. ${ }^{15} \ldots \ldots \ldots \ldots \ldots . . . . . .14$

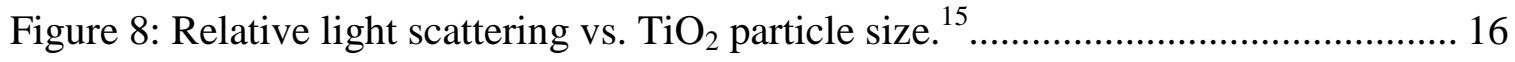

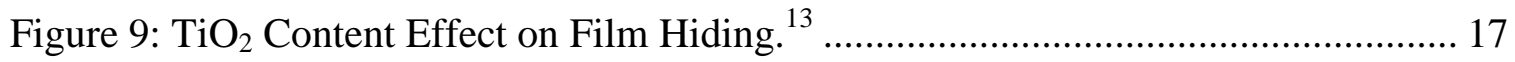

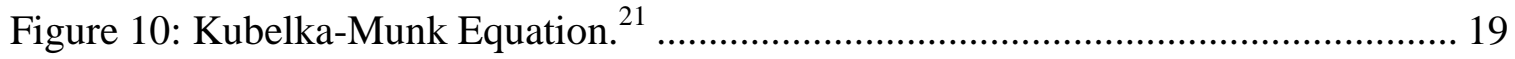

Figure 11: Data output generated by the DuPont Spread Rate Program v2.1 ................ 22

Figure 12: Example of opacity chart light reflectance readings used for spread rate...... 40

Figure 13: Low shear rate viscosity vs. shear rate curves for Formula \#8 variations....... 47

Figure 14: Formula \#8, wet film macroscope image................................................ 49

Figure 15: Formula \#8, 5 minute dry film macroscope image. .................................. 49

Figure 16: Formula \#8, 10 minute dry film macroscope image. .................................. 49

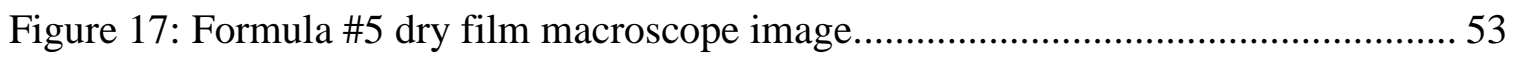

Figure 18: Formula \#8 dry film macroscope image ............................................... 53

Figure 19: Commercial 1 dry film macroscope image. .............................................. 53

Figure 20: Commercial 2 dry film macroscope image. ............................................ 54

Figure 21: Commercial 3 dry film macroscope image. ............................................. 54 


\section{INTRODUCTION}

\subsection{One Coat Interior Architectural Paint}

Interior architectural paints are relied upon to change the aesthetic appearance as well as protect the surfaces inside the buildings in which we dwell. The demand for improved wet and dry film properties of these paints has driven coatings research for decades. Recent innovation has led to the development of paints that have the ability to vanquish old layers with just one coat. These "one coat" paints allow consumers to save time and money by only requiring one painting session and a lesser volume of paint in order to finish a project. One coat paints have been made commercially available in recent years, but these products lack the coverage area per gallon that consumers have grown accustomed to and often have many disclaimers. A full color pallet of one coat paints, with coverage areas that are similar or better than established paints, would be lucrative for both paint manufacturers and consumers.

\subsection{Paint Components}

The inherent complexity associated with paint systems makes achievement of one coat formulations challenging. It is critical for paint formulators to be familiar with the different ingredients that compose paint systems and the complex interactions between them in order to achieve success.

Architectural paints are composed of four basic ingredients - binder, pigments, additives, and solvents. Each ingredient within each category serves a function and the combination of the ingredients is responsible for creating the utility of the coating. 


\subsubsection{Binders}

Arguably, the most important ingredient in a coating is the binder. The binder serves as the film-forming ingredient that combines all of the components together into one cohesive coating and provides adhesion to the substrate. There are many different kinds of binders used for various applications. With today's strict volatile organic compound (VOC) emission standards, latex is commonly used in interior architectural coatings.

Latex is typically composed of vinyl and/or acrylic copolymers synthesized via emulsion polymerization and dispersed in an aqueous medium. Film formation of the binder takes place through coalescence as seen in Figure 1:
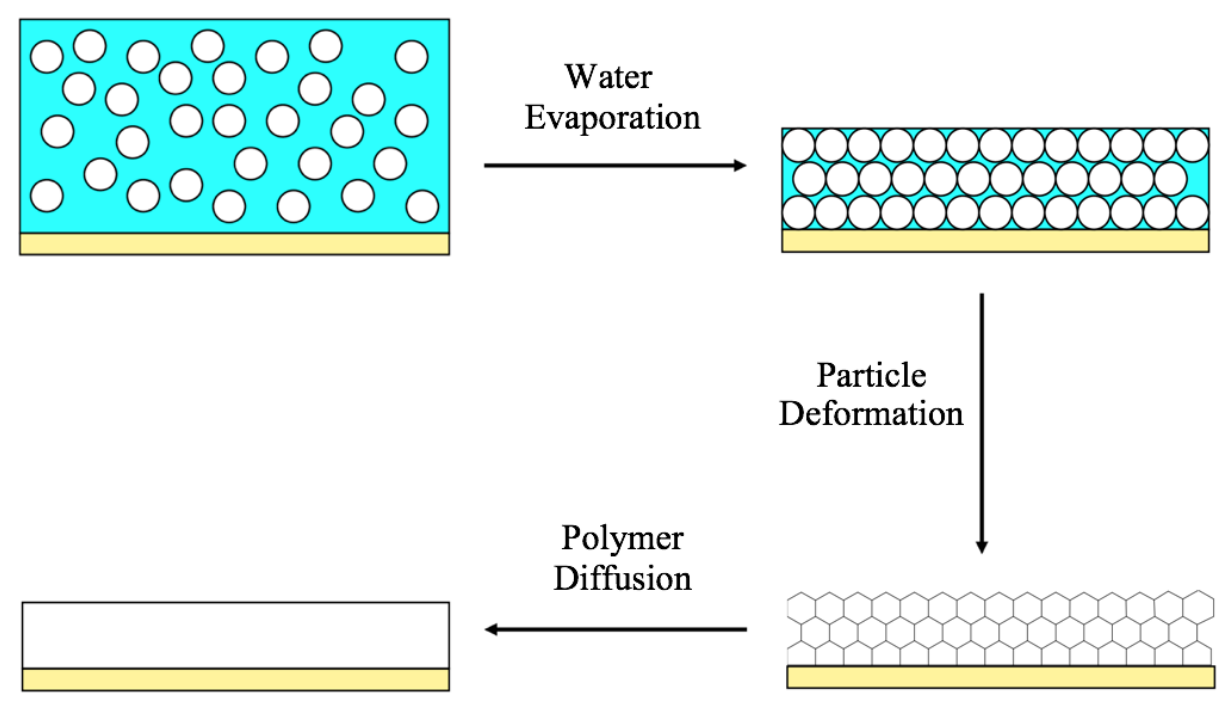

Figure 1: Latex paint film formation process. ${ }^{1}$

The initial phase of film formation occurs after application when the water begins to evaporate. Evaporation drives the polymer particles closer together until the final stage of evaporation where the particles deform due to capillary forces. The individual polymer chains interdiffuse creating the dry film coating. The diffusion of the polymer is highly influenced by paint additives, such as coalescing solvents. 


\subsubsection{Additives}

Additives are materials that are added in small quantities in order to modify one or more properties of the paint. Some examples are coalescing aids, defoamers, dispersing agents, surfactants, biocide, and rheology modifiers. The main additives focused on in this project are rheology modifiers and dispersing agents.

\subsubsection{Rheology Modifiers}

Commonly referred to as thickeners, rheology modifiers are used to viscosify the paint. The various shear forces associated with each stage of the painting process makes controlling the viscosity profile of the system crucial. During settling, sag, and leveling, the paint is exposed to relatively low shear rates, while paint application generates much higher shear forces. The rheology modifiers control how the paint reacts to these forces by controlling the viscosity profile of the coating. There are two categories of thickeners - non-associative thickeners and associative thickeners.

Non-associative thickeners are typically high molecular weight polymers,

composed of a hydrophilic backbone, but lack hydrophobic groups. ${ }^{2}$ The most commonly used non-associative thickeners are cellulosic, with a general structure shown in Figure 2: 


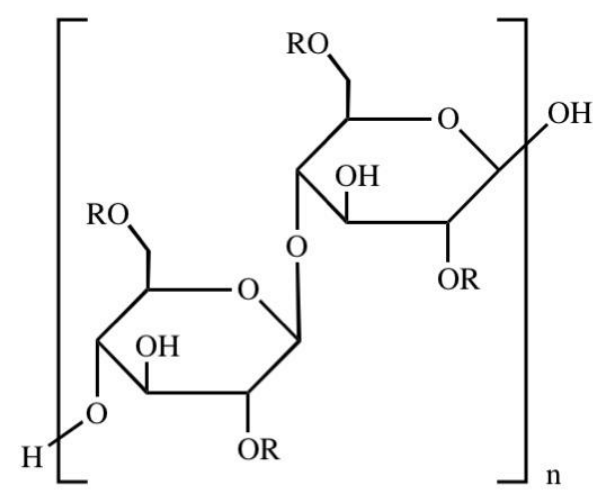

$\mathrm{R}=-\mathrm{CH}_{2} \mathrm{CH}_{2} \mathrm{OH}=$ Hydroxyethyl
$\mathrm{R}=-\mathrm{CH}_{2} \mathrm{COO}^{-} \mathrm{NA}^{+}=$Carboxymethyl
$\mathrm{R}=-\mathrm{C}_{2} \mathrm{H}_{5},-\mathrm{CH}_{2} \mathrm{CH}_{2} \mathrm{OH}=$ Ethyl, Hydroxyethyl
$\mathrm{R}=-\mathrm{CH}_{3},-\mathrm{CH}_{2} \mathrm{CH}_{2} \mathrm{OH}=$ Methyl, Hydroxyethyl

Figure 2: General structure of cellulosic thickeners.

Hydroxyethylcellulose (HEC) is the most commonly used water-soluble cellulosic thickener. There are two primary thickening mechanisms by which HEC thickeners viscosify the paint system - hydrodynamic volume, and chain entanglements.

Hydrodynamic volume refers to the volume of space that the polymer displaces within solution. The high molecular weight polymer occupies a relatively large volume of space while in solution, which immobilizes the water trapped within the polymer coils, leading to increased viscosity. Chain entanglements is the second method by which cellulosic thickeners increase paint viscosity. Chain entanglements are physical interlocks of the flexible polymer chains that are created by intermolecular forces. ${ }^{3}$ The combination of these two methods make cellulosic thickeners an effective viscosifier at a low cost.

The disadvantages of formulating with cellulosic thickeners is that they can lead to poor leveling of the wet film, roller spatter, degradation, and syneresis. Associative thickeners were developed in order to address the problems created by the cellulosic thickeners. ${ }^{4}$ 
Associative thickeners are relatively low molecular weight, hydrophilic polymers with multiple hydrophobic, nonpolar segments. ${ }^{5}$ There are several different types of associative thickeners - hydrophobically-modified ethoxylated urethane (HEUR), hydrophobically-modified alkali-swellable emulsion (HASE), hydrophobically-modified HEC, hydrophobically-modified polyether (HMPE), and hydrophobically-modified aminoplast ether (HEAT). The two associative rheology modifiers experimented with in this project were HEUR and HASE type thickeners. General structures of HEUR and HASE thickeners are shown in Figure 3 and Figure 4, respectively:<smiles>[R]OC(=O)NPNC(=O)NPNC(=O)OCCC(C)(C)OCCOC(C)(C)C(=O)OCC</smiles>

Figure 3: General structure of a HEUR thickener.

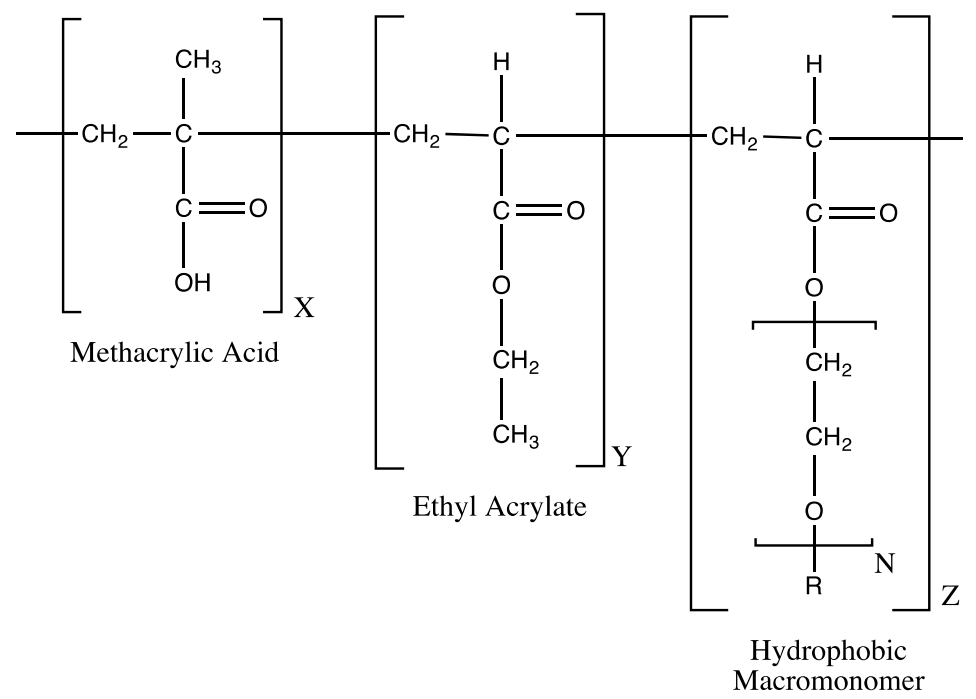

Figure 4: General structure of a HASE thickener. 
HEUR thickeners are commonly used in paint systems that contain a high latex concentration. Upon the addition of associative thickener to the paint system, the watersoluble backbone dissolves and the hydrophobic groups form intramolecular and intermolecular interactions with other hydrophobic ingredients, such as the surface of latex and pigment particles. The interactions can cause micelle-like structure formation and a reversible dynamic network leading to high and mid-shear viscosity build. ${ }^{6}$

The hydrophobic portion of HASE thickeners permits hydrophobic interaction with the other components in the system in a similar fashion as HEUR thickeners. However, HASE thickeners are commonly formulated into crowded systems with a lower latex concentration due to their ability to viscosify through hydrodynamic volume. In an alkaline paint system, the acid monomer constituents can deprotonate resulting in a polyelectrolyte. Electrostatic repulsion leads to an increase in the polymer's hydrodynamic volume, which results in a viscosity increase much in the same way as cellulosic thickeners.

\subsubsection{Dispersants}

A surfactant is a compound that alters the surface tension of a material. They are amphiphilic molecules having both hydrophobic and hydrophilic segments. Surfactants are used in coating formulations to stabilize the system. In latex paints, stabilization occurs through lowering the surface tension of water, making the system thermodynamically stable, which allows for wetting of the pigment particles. ${ }^{7}$ Similar to surfactants, some dispersants are amphiphilic, but are typically classified based on their function rather than their chemical properties. Dispersants are either a non-surface active polymer or a surface-active ingredient added to a suspension to improve particle 
separation and prevent flocculation. ${ }^{8}$ Pigment particles are unstable and have a tendency to flocculate upon addition to the system, which can affect paint film properties. The addition of the dispersant prevents flocculation of the pigment particles by inhibiting the intermolecular interactions that lead to flocculation. The most effective type of dispersants are generally ones with polar functional groups and a less polar tail that is soluble in the solvent medium. ${ }^{9}$

\subsubsection{Solvent}

The volatile ingredients in a coating play a variety of important roles. They have the ability to dissolve the film-forming components, are added to lower the viscosity of the coatings in order to ease application, and they evaporate, making them crucial to the film formation process. ${ }^{9}$ Waterborne systems have become the coating of choice for most interior architectural applications due to ever-increasing VOC emission standards. Volatile organic solvents are still present in many waterborne coatings, but their concentrations are very low.

Coalescing solvents and their evaporation are critical to film formation of latex paints. They aid in the process by softening the polymer, allowing for more efficient deformation and interdiffusion of the individual polymer chains, which leads to continuous film formation and better mechanical properties. ${ }^{1}$ In order for coalescing solvents to be successful, they must evaporate much more slowly than water. High humidity can result in a large amount of the coalscent evaporating before the water, which can devastate the mechanical properties of the dry film. 


\subsubsection{Pigments and Fillers}

The pigment and filler particles within the coating are key to achieving the ideal optical properties for the coating's intended purpose. Pigment particles typically have extreme optical characteristics, are smaller than $10 \mu \mathrm{m}$, are insoluble in water and most organic solvents, and are chemically inert or stable. ${ }^{10}$ Due to these characteristics, pigments have the ability to impart color to the coating system and are added for this reason. Pigments can be categorized as being white, black, colored inorganic, or colored organic. The most commonly used pigment is titanium dioxide $\left(\mathrm{TiO}_{2}\right)$, which is a white particle with unparalleled optical performance and will be discussed further in Chapter 1.5. Carbon black is a commonly used black pigment that, like all colored pigments, has the ability to absorb light. Light scattering at different wavelengths results in the color created by pigments such as in iron oxides. ${ }^{11}$

Like pigment, filler particles are insoluble in most paint solvents. They are added to the paint in order to increase its volume at a low cost. Fillers, also known as extenders, can come from a variety of materials and possess different shapes and sizes. Common shapes include blocks, plates, rods, and other irregular shapes. The size of the particles varies from hundreds of nanometers to micrometers depending on their purpose within the coating. Most fillers have a natural origin, which makes them a cheap alternative to expensive pigment particles, but they contribute very little to optical performance. ${ }^{12}$ Common fillers found in high pigment volume concentration paints include calcium carbonate, kaolin clay (calcined alumina silicate), and diatomaceous earth. ${ }^{9}$ 


\subsection{Pigment Volume Concentration}

The pigment volume concentration (PVC) is a quantitative value used to describe paint composition. The PVC is defined as the volume percentage of pigments and fillers relative to the volume of the dry film. The point at which there is just sufficient binder to coat all of the pigment surfaces is referred to as the critical pigment volume concentration (CPVC). Figure 5 is a model of a coating with increasing PVC:

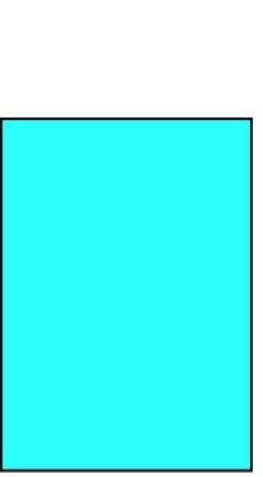

$\mathrm{PVC}=0$

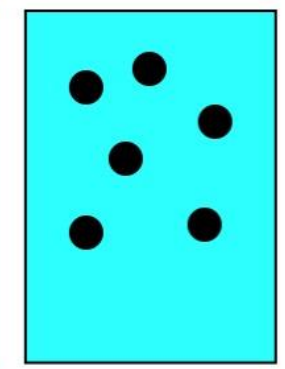

$\mathrm{PVC}<\mathrm{CPVC}$

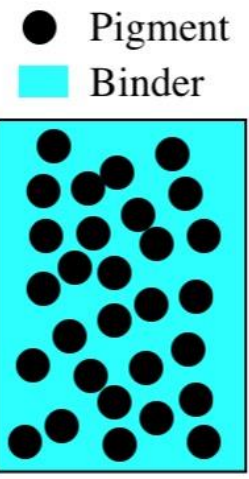

$\mathrm{PVC}=\mathrm{CPVC}$

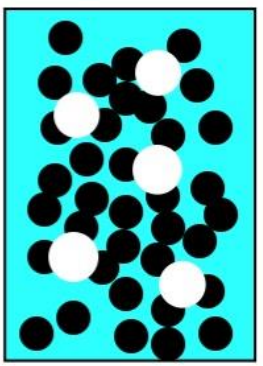

$\mathrm{PVC}>\mathrm{CPVC}$

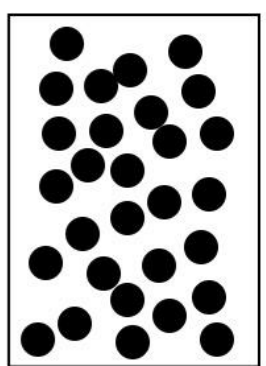

$\mathrm{PVC}=1$

Figure 5: Paint film with increasing PVC. ${ }^{1}$

Formulations above the CPVC do not have sufficient binder to coat all of the particle surfaces and fill the inter-particle voids, leading to air being introduced into the dry paint film, which is represented by the white circles in Figure 5. At the the CPVC, drastic changes in the properties of the coating are observed. Physical properties such as washability, stain and scrub resistance, and tensile strength can be compromised. ${ }^{13}$ The degree of air void formation increases as the PVC increases above the CPVC. The presence of continuous air networks within the dry paint film are responsible for diminished performance.

The CPVC of a coating depends on the packing efficiency of the particles it contains. Factors that affect packing efficiency are particle size distribution, particle 
shape, and particle shape distribution. ${ }^{1}$ Small particles, with high surface areas, require relatively large volumes of binder to fully wet their surfaces. The binder demand required by a pigment or filler product is quantified by the oil absorption value.

\subsubsection{Oil Absorption}

Oil absorption (OA) tests are commonly performed on pigment or filler products in order to determine their affect on the CPVC. ASTM methods D281 and D1483 provide similar procedures to determine the OA value. The methods require the use of a spatula to incorporate linseed oil into $100 \mathrm{~g}$ of pigment until a paste is formed. ${ }^{12}$ The volume of linseed oil needed relates to the OA value of the pigment. High OA value particles are commonly used in flat paints due to their ability to lower the CPVC. These particles, in combination with large filler particles, create surface roughness that can drastically affect the optical properties of the paint.

\subsubsection{Gloss}

Gloss is a crucial optical paint property that must be ideal for the desired application. Gloss measurements are commonly taken at $20^{\circ}, 60^{\circ}$, and $85^{\circ}$ from the normal axis using a glossmeter. Steeper measurement angles are less sensitive to light reflection, therefore, $20^{\circ}$ and $60^{\circ}$ measurements are typically taken for film's with high gloss values while $85^{\circ}$ measurements are used for film's with low gloss. The $85^{\circ}$ gloss value is commonly referred to as the sheen.

Different paint systems are classified largely by the gloss that they create, as seen in Table $1^{1}$ : 
Table 1: Paint Classification and Gloss Value

\begin{tabular}{c|c|c}
\hline Paint Classification & Gloss & Measurement Angle \\
\hline High Gloss & $>65$ & $60^{\circ}$ \\
Semi-Gloss & $30-65$ & $60^{\circ}$ \\
Satin & $15-35$ & $60^{\circ}$ \\
Eggshell & $5-20$ & $60^{\circ}$ \\
Flat & $<5$ & $85^{\circ}$ \\
\hline
\end{tabular}

Unsurprisingly, high gloss paints have high gloss measurements, while flat paints have the lowest gloss measurements. Gloss is determined by the difference between diffuse and specular light reflection. Models of these two modes of light reflection are displayed in Figure 6:
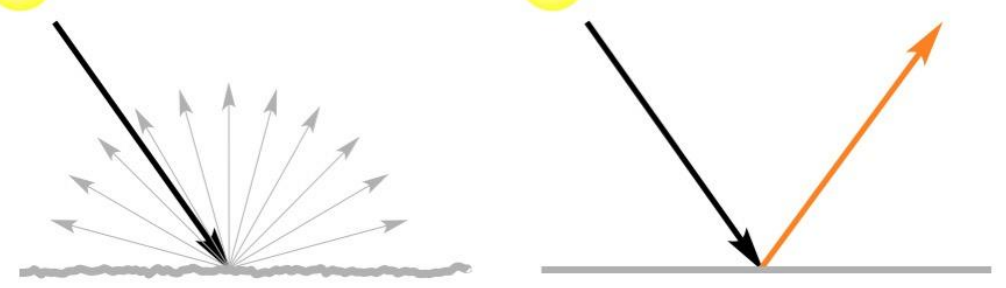

Figure 6: Diffuses reflection (left) and specular reflection (right). ${ }^{1}$

Specular light reflection is defined as the mirror-like reflection of light from a surface, in which incident light from a single direction is reflected into a single outgoing direction. ${ }^{14}$ Large amounts of specular light reflection produced by a coating results in the perception of a glossy finish, due to much of the reflected light reaching the retina in the human eye. Alternatively, diffuse reflection occurs when incident light incoming from a single direction is reflected at many angles, creating light scattering. Films with high degrees of diffuse light reflection allow for only a fraction of the light reflected from the coating's surface to reach the human eye. The lack of light perceived by the visual sense creates the low gloss, flat appearance. 
Paint films have varying degrees of gloss based on their components. As mentioned previously, large particles, in combination with small particles with high OA values, are efficient at creating surface roughness, which accounts for large amounts of diffuse light reflection. Coatings formulated above the CPVC have a high degree of diffuse light reflection due to the pigment and filler particles creating protrusions out from the film's surface. Many flat paints are formulated above the CPVC in order to maximize the coating's diffuse light reflection. In paints that are formulated well above the CPVC, it is possible for the large, platy filler particles to create a somewhat flat top layer on the surface of the coating. This flat layer creates an increase in gloss due to added specular light reflection. The added gloss can be detrimental to the optical standards of flat paints.

\subsection{Hiding Power}

One of the main functions of architectural paint is to hide a surface. Hiding power is defined as how well paint hides a substrate from view. In order to gain hiding power, light must be inhibited from reaching the substrate's surface. The paint film can accomplish this by absorbing the light or scattering it away from the substrate. Colored paints have an advantage by bearing the ability to absorb light, while white paints rely solely on light scattering.

Refractive index is a measure of how well a material bends light. An ingredient with a high refractive index is beneficial to the paint film because it diverts light way from the substrate to a great extent. A list of refractive indices for common paint ingredients is shown in Table 2: 
Table 2: Refractive Indices of Common Ingredients ${ }^{1}$

\begin{tabular}{c|c}
\hline Ingredient & Refractive Index \\
\hline Air & 1.00 \\
Binder & $1.47-1.55$ \\
Silica & $1.41-1.49$ \\
Calcium Carbonate & 1.63 \\
Kaolin Clay & 1.65 \\
Zinc Oxide & 2.02 \\
$\mathrm{TiO}_{2}$ (Anatase) & 2.55 \\
$\mathrm{TiO}_{2}$ (Rutile) & 2.73 \\
\hline
\end{tabular}

The magnitude of a film's hiding power is determined by the square of the difference in refractive indices between adjacent materials. ${ }^{13}$ For this reason, paint films containing air voids are more efficient at scattering light because the air presence decreases the average refractive index of the binder matrix. The difference in refractive index between the air-containing matrix and $\mathrm{TiO}_{2}$ particles is larger than the difference between the air-free binder and $\mathrm{TiO}_{2}$. Therefore, dry paint films containing air voids maximize their hiding power potential.

\subsubsection{Contrast Ratio}

The hiding power of paint can be described quantitatively by its contrast ratio. The contrast ratio is the measurement of the hiding of paint without distinction between contributions from light scattering and absorption. ${ }^{10}$ It is expressed as the quotient of reflectance of a paint film measured over a black and white substrate on an opacity chart. The reflectance value is the $\mathrm{Y}$ tristimulus and the maximum value of the quotient is 1 . The term "complete hiding" is used when the film achieves a contrast ratio of 0.98 or higher. The human eye cannot detect the difference between substrate color at this level of hiding. $\mathrm{TiO}_{2}$ is the main source of hiding power in virtually all white paints. 


\subsection{Titanium Dioxide}

In recent decades, titanium dioxide $\left(\mathrm{TiO}_{2}\right)$ has become the ultimate white pigment added to paint coatings. Its lack of visible light absorption in combination with its superior ability to scatter light makes $\mathrm{TiO}_{2}$ the best white pigment available. ${ }^{10} \mathrm{TiO}_{2}$ is commercially available in two crystal structures - anatase and rutile. A comparison of light reflectance for both $\mathrm{TiO}_{2}$ structures is shown in Figure 7:

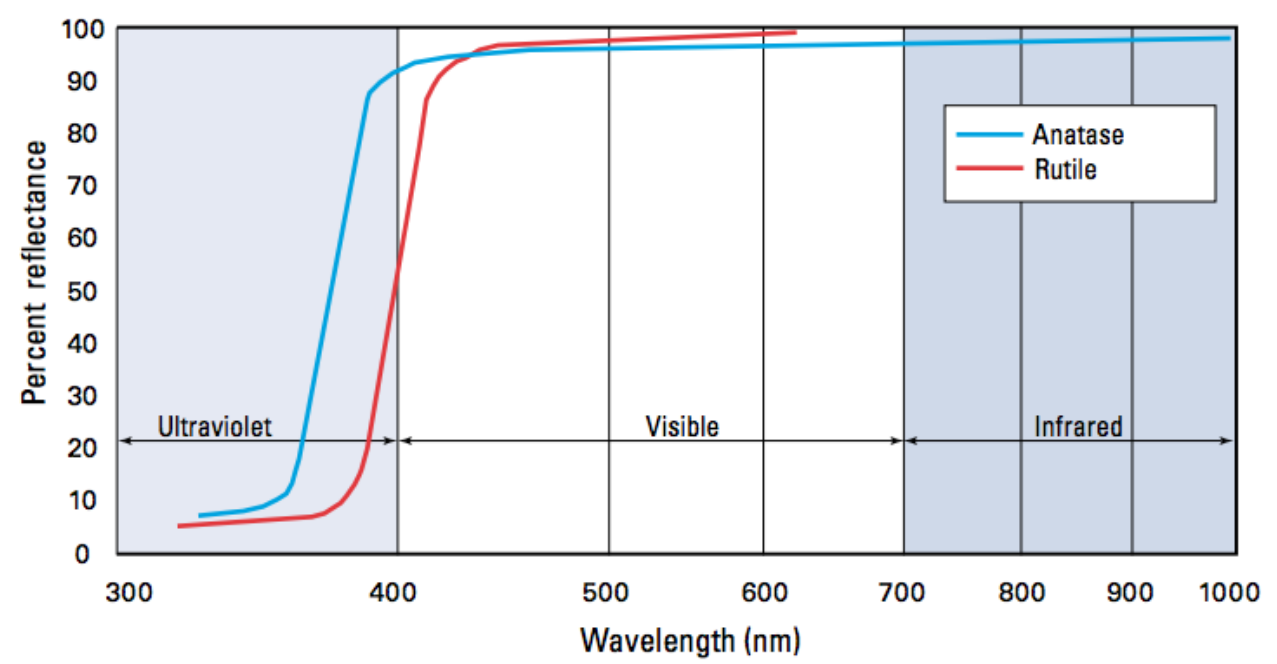

Figure 7: Reflectance of $\mathrm{TiO}_{2}$ pigment in various regions of the spectrum. ${ }^{15}$

The red line indicates that rutile $\mathrm{TiO}_{2}$ scatters most visible wavelengths of light more efficiently than anatase $\mathrm{TiO}_{2}$. Rutile pigment's superior light scattering is due to its greater refractive index. Rutile $\mathrm{TiO}_{2}$ is also more stable and more durable than anatase pigments. For these reasons, rutile $\mathrm{TiO}_{2}$ pigments are preferred over anatase $\mathrm{TiO}_{2}$ in paint formulations.

\subsubsection{Production Methods}

There are two methods for producing titanium dioxide pigments - the sulfate process and the chloride process. The sulfate process is a relatively low-technology, batch manufacture technique, which was developed in the early 1900s, whereas the chloride 
process is a more high-technology, continuous process commercialized by DuPont in the 1950s. ${ }^{16}$ Pigment particles from either process are surface-treated with inorganic oxides and hydroxides. The pigment is then filtered, washed, dried, and then may receive a finishing treatment with organics before being ground and packed or slurried with dispersants.

\subsubsection{Pigment Grades}

The type and degree of finishing treatment supplied to the $\mathrm{TiO}_{2}$ depends on its application. ${ }^{16}$ Universal grade $\mathrm{TiO}_{2}$ products, used for a variety of applications within the coatings industry, undergo a relatively light surface treatment process and are therefore considered to have a high $\mathrm{TiO}_{2}$ content. Flat grade pigments get encapsulated in a thick layer of engineered silica and alumina creating a porous and voluminous coating on the surface of the $\mathrm{TiO}_{2}$ particles. ${ }^{17}$ These highly treated $\mathrm{TiO}_{2}$ products have typically higher oil absorption than universal pigment grades, which significantly decreases the critical pigment volume concentration. Flat grade pigments are most effective in formulations above or near the CPVC, where gloss values are low, hence the name flat grade pigment.

\subsection{Scattering Theory}

As previously mentioned, the refractive index is a great way to quantify light scattering performance. However, the true light scattering efficiency of $\mathrm{TiO}_{2}$ within in a dry paint film is not equal in all paints. A number of factors including particle size, particle size distribution, shape, dispersion, degree of aggregation and flocculation, and pigment concentration (PVC) affect the light scattering performance of the pigment. ${ }^{18}$ 


\subsubsection{Particle Size}

The particle size of the pigment particles is integral in determining its light scattering efficiency. The relative light scattering power of rutile $\mathrm{TiO}_{2}$ for blue, green, and red light as a function of particle size is shown in Figure 8:

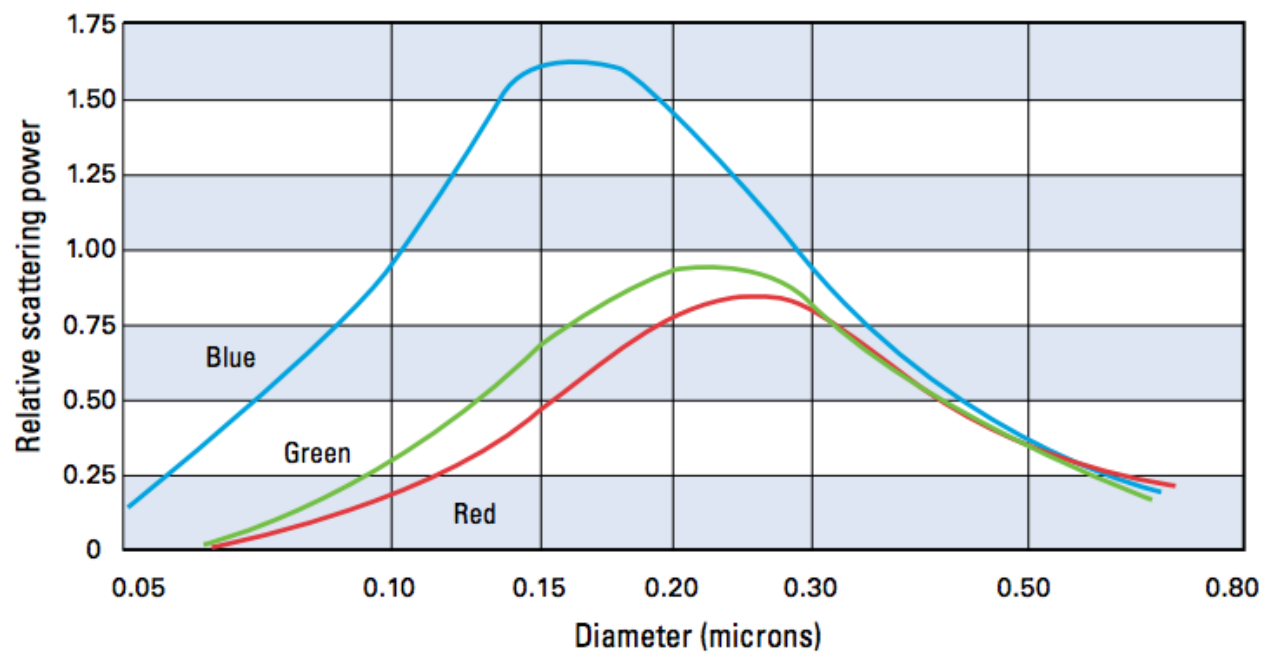

Figure 8: Relative light scattering vs. $\mathrm{TiO}_{2}$ particle size. $^{15}$

The human eye is most sensitive to wavelengths around 0.55 microns, which corresponds to yellow - green light. Therefore, the optimum particle size for $\mathrm{TiO}_{2}$ pigment is between 0.2 and 0.3 microns. ${ }^{15}$ According to the graph in Figure 8, this particle size creates maximum green and red light scattering and significant blue light scattering. An extremely important factor that helps determine the optimum $\mathrm{TiO}_{2}$ particle size is diffraction of the light waves.

\subsubsection{Diffraction}

Diffraction occurs when waves bend as they pass by an object. Just as water wraps around a stone in a river, incident light waves will bend around a pigment particle and scatter. When the size of the $\mathrm{TiO}_{2}$ particles are about half the wavelength of incident light, the particles can bend four to five times as much light as actually falls on the 
particle surface because a large amount of the light is diffracted as it passes close by the particles. ${ }^{15}$ Unsurprisingly, $\mathrm{TiO}_{2}$ pigment products tend to be marketed at around 0.3 microns, where light scattering is optimized.

\subsubsection{Crowding}

Particles are in abundance within a paint film, particularly in high PVC formulations. The shear number of particles within a fixed volume creates a "crowding" effect within the system, which reduces the light scattering efficiency of each particle. ${ }^{13}$ For this reason, formulations are engineered to maintain optimal particle separation, as much as possible, in order to maximize light scattering. The affects of pigment particle crowding on light scattering can be seen in Figure 9:

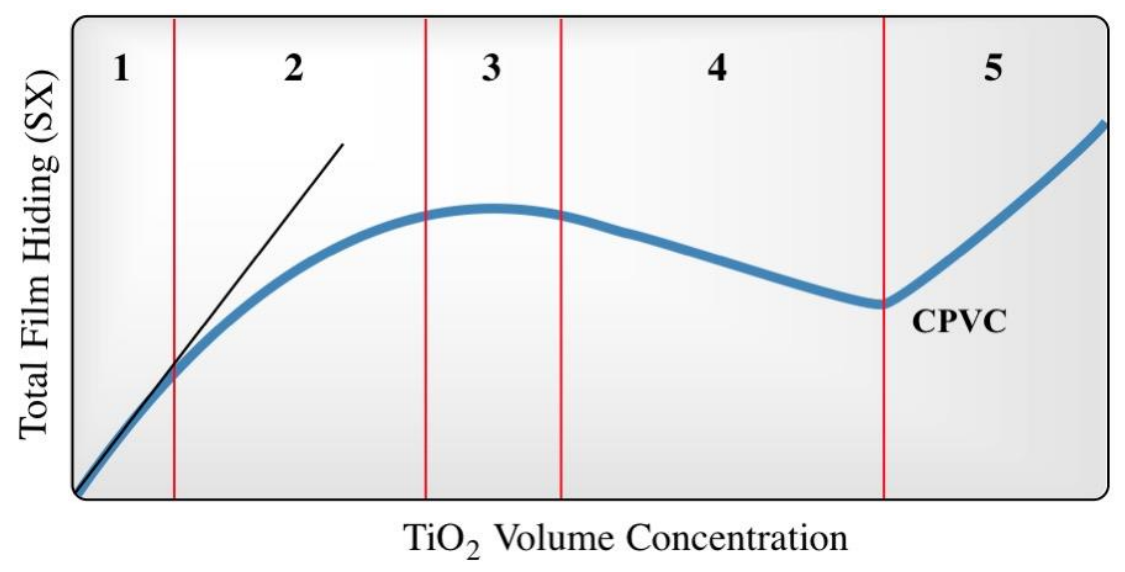

Figure 9: $\mathrm{TiO}_{2}$ Content Effect on Film Hiding. ${ }^{13}$

$\mathrm{TiO}_{2} \mathrm{PVC}$ effect on hiding can be summarized in five parts. ${ }^{13}$ In the first section, an addition of pigment gives an equal (straight black line) addition of total hiding to the paint system. At low levels of PVC, the pigment particle separation is vast enough that the light scattering efficiency is maximized by all of the particles due to the lack of crowding effects. The second section displays the first sign of $\mathrm{TiO}_{2}$ crowding effects. In this section, addition of pigment yields increased hiding power. However, some amount 
of particle packing leads to less than optimal light scattering. Therefore, a non-linear, but positive increase in hiding is observed. In the third section, addition of $\mathrm{TiO}_{2}$ pigment does not increase hiding in the film. The addition of light scattering centers is offset by the decrease in scattering efficiency due to crowding. Further pigment addition, into section four, actually decreases film light scattering due to massive particle crowding. Up to a $20 \%$ loss in scattering power results from pigment particle crowding effects. The crowding causes overlap of the optical cross-sections that are responsible for light diffraction. ${ }^{19,20}$ This trend continues until the CPVC is reached, where the crowding is at its maximum. Above the CPVC in section five, further addition of pigment yields air void formations. The presence of air voids in the paint film creates an abrupt increase in light scattering because the air decreases the average refractive index of the binder. As stated earlier, the magnitude of light scattering is determined by the square of the difference between two adjacent materials, in this case the binder and the pigment. Additionally, if the air voids are of optimal size (approximately $0.3 \mu \mathrm{m}$ ), they will scatter light as the wave enters and exits the void. ${ }^{13}$ This affect is similar to that of $\mathrm{TiO}_{2}$, but not as effective because the difference in refractive index between the air and binder is smaller than the difference between the binder and pigment. Nonetheless, air voids are beneficial to hiding power, and can greatly affect a paint's spread rate.

\subsection{Spread Rate}

An important characteristic of an architectural paint is it's spread rate. Spread rate is the amount of area a volume of paint covers while obtaining complete hiding and is typically expressed in $\mathrm{ft}^{2} / \mathrm{gal}$. The Spread Rate Program v2.1 (DuPont) utilizes KubelkaMunk relationships to extrapolate and interpolate the spread rate. ${ }^{21}$ 


\subsubsection{Kubelka-Munk}

The Kubelka-Munk theory takes a macroscopic approach to light scattering, which is more applicable to paint systems than the Mie Theory because of the crowded nature of the formulations. ${ }^{21,22}$ Kubelka and Munk founded a set of equations that relate the brightness, contrast ratio, and quantity of light scattering centers in a pigmented film (DuPont, 2002). The theory considers the scattering and absorption of light by thin films based on reflectivities. The equation that they derived is shown in Figure 10:

$$
\mathrm{R}=\frac{\frac{\left(R_{g}-R_{\infty}\right)}{R_{\infty}}-\left(R_{g}-\frac{1}{R_{\infty}}\right) e^{S X\left(\frac{1}{R_{\infty}}-R_{\infty}\right)}}{\left(R_{g}-R_{\infty}\right)-\left(R_{g}-\frac{1}{R_{\infty}}\right) e^{S X\left(\frac{1}{R_{\infty}}-R_{\infty}\right)}}
$$

\section{Figure 10: Kubelka-Munk Equation. ${ }^{21}$}

Where, the reflectance, $\mathrm{R}$, is found by obtaining the background substrate reflectance, $\mathrm{R}_{\mathrm{g}}$, the scattering power, SX, and the reflectance of a thick film, $\mathrm{R}_{\infty}$, such that the reflectance does not change. The SX term is dimensionless but is a product of the scattering coefficient, S, and the amount of scattering material or thickness, $\mathrm{X}$. The $\mathrm{S}$ term is constant for each coating formulation, while altering the amount of paint applied to the substrate changes the SX value. The X term can be expressed in units of film thickness or coverage area making the units of $\mathrm{S}$ the reciprocal of $\mathrm{X}$ (e.g. $\left.\mathrm{mil}^{-1} \mathrm{or}^{2} / \mathrm{gal}\right)$. The $\mathrm{X}$ term can also be referred to as the spread rate.

As for the pigment concentration effects on spread rate, the trend is the same as that shown in Figure 10 above. ${ }^{13}$ Introducing air voids into the dry paint film greatly increases the spread rate. For this reason, ultra-high spread rate, flat paints are commonly formulated above the CPVC. 


\section{MATERIALS AND METHODS}

All materials were obtained from commercially available sources. A VMAGetzmann Dispermat was used to blend and mix the materials. Leneta Opacity 14-H charts were used for spread rate determination. ICI viscosity measurements were taken on a BYK Cap 1000+ Viscometer and a Brookfield KU-2 Viscometer was used for 24 hour KU viscosity measurements. Rheology was performed on a Texas Instruments HR-2 hybrid rheometer equipped with a $40 \mathrm{~mm}, 2^{\circ}$ cone, and a $55 \mu \mathrm{m}$ gap. Viscosities were measured in steady-flow mode in the shear rate range of $0.01-1000 \mathrm{~s}^{-1}$. A BYK-Gardner haze-gloss meter was used for $85^{\circ}$ gloss (sheen) data collection. Reflectance data for spread rate determination was collected on an x-rite VS450 non-contact spectrophotometer with Color iQC software. A Keyence VR-3000 series One-Shot 3D Measuring Macroscope was used to obtain surface roughness measurements of dry films.

\subsection{Spread Rate Procedure}

An automatic drawdown vacuum plate and a drawdown bar that gave a contrast ratio between 0.92 and 0.95 was used to create four, weighed drawdowns on specially cut, Leneta Opacity 14-H charts, for each paint. Each chart contains two sets of alternating white and black substrates, giving a total of four squares. Paints were stirred slowly prior to each drawdown, and then the paint was applied onto the Leneta chart. The paint was pushed to the back of the drawdown bar in order to ensure the paint coverage area of $54.2 \mathrm{in}^{2}$ was constant for each drawdown. Additionally, each drawdown was weighed, such that drawdowns for each paint sample were within \pm 0.06 grams of each other. Immediately after completing each drawdown, an x-rite VS450 spectrophotometer was used to measure the light reflectance for each of the four squares on the chart. The 
reflectance values were collected again after letting the paint dry for 24 hours in a drying cabinet. In order to quantitatively observe the hiding affects due to air contribution, the reflectance values were gathered for a third time after mineral oil was brushed onto the dry film and left to level horizontally for 30 minutes. Mineral oil has a similar refractive index as the binder matrix, therefore, when it penetrates and fills the air voids in the dry paint film, the increased hiding power created by the air voids disappears. The reflectance of the Leneta charts was taken into account by measuring the reflectance over the white substrate of ten randomly selected charts per box.

\subsection{Spread Rate Calculation}

The DuPont Spread Rate Program v2.1 was used to generate spread rate values for each paint sample. This program utilizes Kubelka-Munk relationships to extrapolate and interpolate the $\mathrm{X}$ value. Input variables needed to calculate spread rate include the paint density, $\mathrm{TiO}_{2}$ content, reflectance over white, reflectance over black, substrate reflectance, drawdown weight, and drawdown coverage area. Spread rate, scattering (S), and thickness $(\mathrm{X})$ are a few useful values generated by the program at complete hiding. Additional parameters, such as $\mathrm{R}_{\infty}$, are not used in this study for simplicity. A screenshot of the Spread Rate Program is shown in Figure 11: 


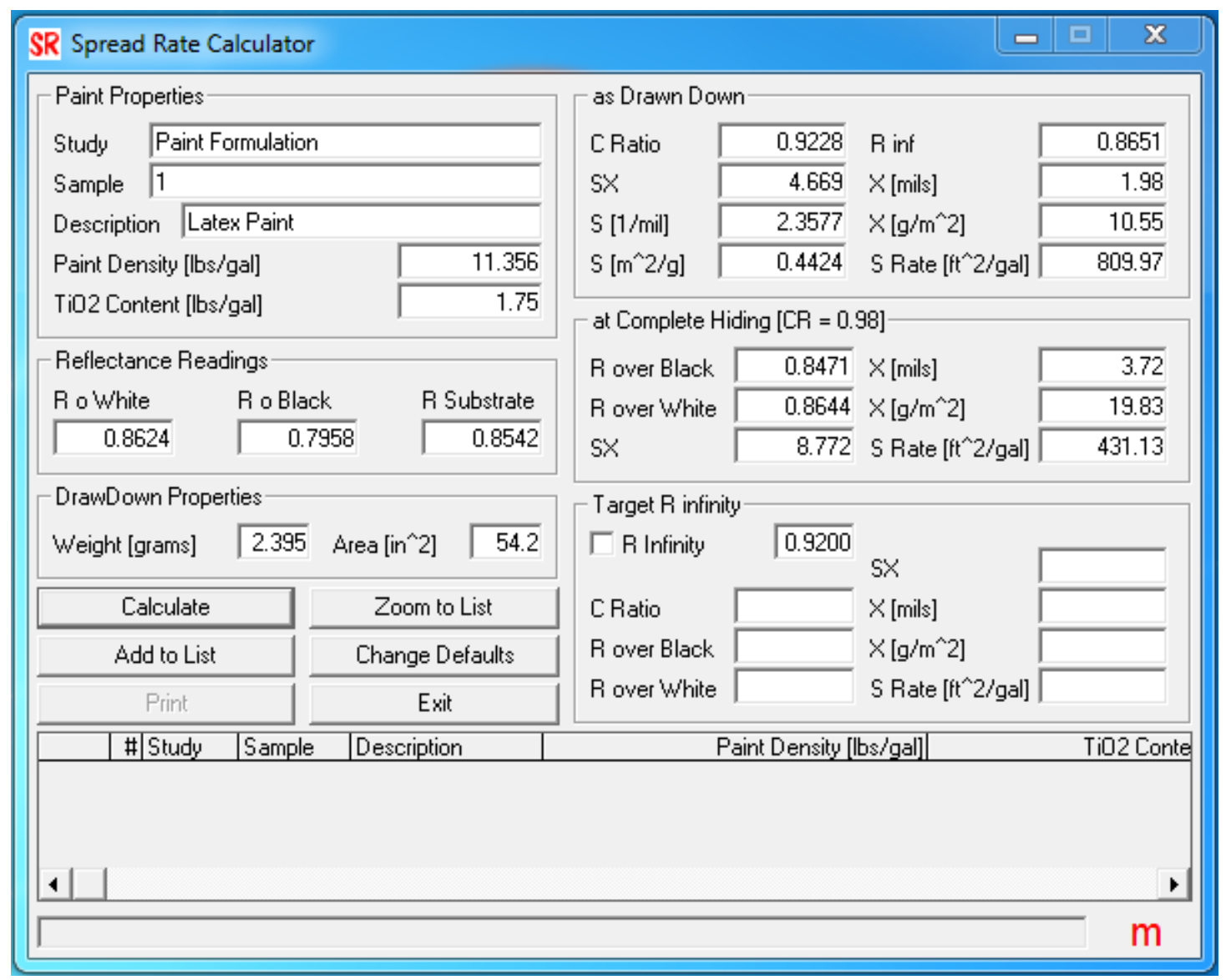

Figure 11: Data output generated by the DuPont Spread Rate Program v2.1. 


\section{RESULTS AND DISCUSSION}

\subsection{Formula \#1}

The goal of this project is to create an interior flat, white latex paint that yields a spread rate of greater than $400 \mathrm{ft}^{2} / g a l$. as advertised by many below critical commercial paints. Ideally, the spread rate should be at least $600 \mathrm{ft}^{2} /$ gal and attempt to approach 800 $\mathrm{ft}^{2} /$ gal. In order for the paint to be considered flat, it must have an $85^{\circ}$ gloss, or sheen, measurement of less than 5.0. The paint must also have a low-shear rate viscosity of around $100 \mathrm{KU}$ and a high-shear rate viscosity (ICI) of around 1.00 P. The first paint formulation tested in this study was derived in North America and will be referred to as Formula \#1. The specifics of the formulation are shown in Table 3 and the Appendix, along with the properties of the pigment and extender particles used in the formulation:

Table 3: Formula \#1 Formulation

\begin{tabular}{|c|c|}
\hline Material Name & Amount (\%) \\
\hline Water & Grind \\
\hline Inorganic Dispersant & $12-20$ \\
Dispersant A & $0.1-0.3$ \\
Glycol & $0.1-0.3$ \\
Coalescent Aid & $0.5-2.0$ \\
Defoamer & $1-4$ \\
2\% Solution HEC A & $0.1-0.3$ \\
Chemours@ Flat Grade TiO 2 & $4-8$ \\
Kaolin Clay & $19-23$ \\
CaCO & $4-6$ \\
Diatomaceous Earth & $15-20$ \\
2\% Solution HEC A & $1-4$ \\
Latex A & $12-17$ \\
Neutralizer & $13-16$ \\
Water & $0.1-0.3$ \\
HASE Thickener & $0.2-0.5$ \\
\hline \%NVW - 52\%; \% NVV - 31\%; PVC - >60\%; $\mathrm{TiO}_{2}=2.3-3.1 \mathrm{lb} / \mathrm{gal}$ \\
\hline
\end{tabular}


Viscosity, gloss, and spread rate measurements of Formula \#1 led to the results shown in Table 4:

Table 4: First Trial Data for Formulation \#1

\begin{tabular}{|c|c|c|c|c|}
\hline Paint Sample & KU & ICI (P) & Sheen & Spread Rate $\left(\mathbf{f t}^{2} / \mathbf{g a l}\right)$ \\
\hline Formula \#1 & 73.4 & 0.683 & 9.2 & 585 \\
\hline
\end{tabular}

Both the 24-hour KU (73.4) and high-shear rate (0.683 P) viscosities were significantly lower than the goal of $100 \mathrm{KU}$ and $1.00 \mathrm{P}$. The sheen (9.2) and spread rate (585 $\mathrm{ft}^{2} / \mathrm{gal}$ ) values were also far from the desired values of $<5.0$ and $>600 \mathrm{ft}^{2} / \mathrm{gal}$.

\subsubsection{Formula \#1 Variations}

Variations of Formula \#1 were attempted to garner more optimal paint properties. Details of the variations are shown in Table 5:

Table 5: Formula \#1 Variations

\begin{tabular}{c|c}
\hline Paint & Variation \\
\hline Variation A & All Thickener Added in Letdown Step \\
Variation B & 25\% Less Coalescent \\
Variation C & 20\% More HEC \\
\hline
\end{tabular}

Data comparing the viscosities, sheen, spread rate, and relative light scattering of Formula \#1 and its variations are shown in Table 6:

Table 6: Data for Formula \#1 Variations

\begin{tabular}{|c|c|c|c|c|c|c|c|}
\hline \multirow{2}{*}{ Paint } & \multirow{2}{*}{ KU } & \multirow{2}{*}{ ICI (P) } & \multirow{2}{*}{ Sheen } & Spread Rate & \multicolumn{3}{|c|}{ Relative Light Scattering } \\
\cline { 5 - 8 } & & & & $\left.\mathbf{f t}^{\mathbf{2}} \mathbf{g a l}\right)$ & Wet & Dry & Oiled \\
\hline Formula \#1 & 73.4 & 0.683 & 9.2 & 585 & 100 & 100 & 100 \\
Variation A & 75.2 & 0.646 & 8.3 & 607 & 100.4 & 99.4 & 96.7 \\
Variation B & 73.2 & 0.713 & 9.7 & 580 & 101.2 & 100 & 95.1 \\
Variation C & 74.2 & 0.714 & 8.6 & 543 & 93.5 & 98.6 & 90.9 \\
\hline
\end{tabular}

Introducing the thickener in the letdown stage (Variation A) resulted in favorable changes to the paint properties by slightly increasing the spread rate, $\mathrm{KU}$, and air void formation, while decreasing the sheen. The difference in relative light scattering between 
the dry and oiled film quantifies a $2.7 \%$ increase in light scattering due to air when all of the thickener was added during the letdown step. The hiding created by the added air led to a slight increase in spread rate when compared to Formula \#1. The sheen value fell due to increased diffuse light scattering, which may be attributed to a rougher surface due to the added air presence, but this was not the case for the variation consisting of $25 \%$ less coalescent (Variation B). The hypothesis was that by taking out some of the coalescent, a rougher surface with more air voids would be created. The latter part of the hypothesis, concerning the creation of air voids, is true. However, the sheen value was higher relative to both Formula \#1 and Variation A. This result was unexpected because the coalescent aid allows the latex polymer to coalesce into a continuous film, which can create a glossy finish. By removing $25 \%$ of the coalescent, the individual latex polymer chains should not be able to interdiffuse as well and a glossy finish should be avoided. Somehow the specular light reflection increased with the decrease in coalescent concentration.

Removing $25 \%$ of the coalescent did not affect the spread rate or viscosity, therefore, Variation B was not an improvement. Increasing the HEC concentration by $20 \%$ (Variation C) did not result in the significant viscosity increase that was expected. It is possible that the viscosity did not increase significantly because the dispersion quality was not sufficient. This hypothesis was supported by the relative light scattering value for the wet film. The $6.5 \%$ decrease in light scattering, relative to Formula \#1, suggests that either there was less $\mathrm{TiO}_{2}$ in Variation $\mathrm{C}$ or the pigment particles were slightly aggregated. The latter of the two possibilities is the more likely explanation because the relative light scattering increased once the film had dried. Although sampling error is always present due to the natural inconsistency of adding ingredients to the formulation, 
both the lower than expected viscosity and the light scattering values indicate that Variation $\mathrm{C}$ achieved a less than perfect dispersion state during its formulation. Although there was more air present in the dry paint film, relative to Formula \#1, the added air did not help to increase the spread rate. None of the three Formula \#1 variations reached the desired viscosity threshold.

Although it was found that adding the thickener in the letdown stage led to more preferential properties, the lack of thickener during the grind resulted in a very low viscosity grind state that is less than ideal for grinding the particles. For this reason, the original method for thickener addition was maintained.

\subsubsection{HEC Molecular Weight}

The next set of variations attempted to reach the viscosity goal by adjusting the hydroxyethylcellulose (HEC) molecular weight (MW), as summarized in Table 7:

Table 7: HEC Thickener Molecular Weights

\begin{tabular}{c|c}
\hline Paint & HEC Molecular Weight \\
\hline HEC A & $7.2 \times 10^{5}$ \\
HEC B & $1.0 \times 10^{6}$ \\
HEC C & $1.3 \times 10^{6}$ \\
\hline
\end{tabular}

Formula \#1 variations HEC A to HEC C were each formulated with a different cellulosic thickener of increasing MW. Comparison results of the variations are shown in Table 8:

Table 8: Data for Formula \#1 HEC Variations

\begin{tabular}{|c|c|c|c|c|c|c|c|}
\hline \multirow{2}{*}{ Paint } & \multirow{2}{*}{ KU } & \multirow{2}{*}{ ICI (P) } & \multirow{2}{*}{ Sheen } & $\begin{array}{c}\text { Spread Rate } \\
\left(\mathbf{f t}^{\mathbf{2}} \text { /gal) }\right.\end{array}$ & \multicolumn{3}{|c|}{ Relative Light Scattering } \\
\cline { 5 - 8 } & & & & Wet & Dry & Oiled \\
\hline HEC A & 73.4 & 0.683 & 9.2 & 585 & 100 & 100 & 100 \\
HEC B & 96.3 & 1.000 & 10.8 & 595 & 95.7 & 98.0 & 95.8 \\
HEC C & 85 & 0.737 & 10.8 & 608 & 92.7 & 99.6 & 96.3 \\
\hline
\end{tabular}


The highest MW thickener (HEC C) raised the high and low-shear viscosities from the original value obtained with Formula \#1 (HEC A). However, it did not thicken the paint as well as HEC B, which is of lower MW. Similar to Variation 3 in the last set of experiments, it is possible that the HEC C formulation did not sufficiently disperse after being added as a $2 \%$ solution to the mixing paint. This hypothesis is again supported by the low wet film relative light scattering value. No matter the reason, HEC B achieved more optimum KU and ICI viscosities of 96.3 KU and 1.00 P for the low and high-shear viscosities, respectively. The sheen increased from the original Formula \#1 value of 9.2 to 10.8 after switching to HEC B, while the spread rate was similar. It is unclear why the sheen increased as dramatically as it did, but may be due to the increased viscosity or simple batch to batch dispersion variability and film formation inconsistency. The slightly higher spread rate is most likely due to the increased air contribution. Despite the increased sheen value, it was determined that HEC B should be used instead of HEC A in order to achieve a more optimized viscosity behavior. The new formula containing the Formula \#1 ingredients with replacement of the higher MW HEC will be referred to as Formula \#2 and is shown in the Appendix.

\subsection{Formula \#2}

\subsubsection{Grind Conditions}

Inconsistent dispersion states in the previous formulations were a concern. Therefore, the grind time was varied in order to observe for overgrinding or any other trend regarding the dispersion of Formula \#2. The grind time variations are summarized in Table 9: 
Table 9: Formula \#2 Grind Time Variations

\begin{tabular}{c|c}
\hline Paint & Grind Time (min) + Conditions \\
\hline Grind 1 & 15 \\
Grind 2 & $15+*$ DE in Letdown \\
Grind 3 & 20 \\
Grind 4 & 10 \\
Grind 5 & 5 \\
\hline
\end{tabular}

Grind 1 is the control, which maintains a 15 minute grind that is consistent with the previous formulations. Grind 2 features the addition of the diatomaceous earth at the end of the 15 minute grind. It has been hypothesized that the minerals in the diatomaceous earth (DE) get pulverized during the high-shear grind stage and lose their large particle size. Addition of these particles at the end of the grind should prevent such particle decomposition. Grinds $3-5$ had decreasing grind times and the addition of Diatomaceous earth occurred at the beginning of the grind, as it was in Grind 1 and the previous formulations. Data results from the Formula \#2 grind time variations are compared in Table 10:

Table 10: Data for Formula \#2 Grind Time Variations

\begin{tabular}{|c|c|c|c|c|c|c|c|}
\hline \multirow{2}{*}{ Paint } & \multirow{2}{*}{ KU } & \multirow{2}{*}{ ICI (P) } & \multirow{2}{*}{ Sheen } & $\begin{array}{c}\text { Spread Rate } \\
\left(\mathbf{f t}^{2} \text { /gal) }\right.\end{array}$ & \multicolumn{3}{|c|}{ Relative Light Scattering } \\
\cline { 5 - 8 } & & & & Wet & Dry & Oiled \\
\hline Grind 1 & 95.4 & 0.946 & 11.2 & 615 & 100 & 100 & 100 \\
Grind 2 & 96.0 & 0.971 & 11.4 & 609 & 101.4 & 99.1 & 97.9 \\
Grind 3 & 95.7 & 0.871 & 11.2 & 556 & 96.9 & 92.9 & 98.1 \\
Grind 4 & 95.6 & 0.900 & 11.3 & 545 & 97.5 & 92.9 & 96.7 \\
Grind 5 & 95.9 & 0.979 & 11.5 & 613 & 105.3 & 93.5 & 101.5 \\
\hline
\end{tabular}

The spread rate did not seem to follow a trend with respect to grind time. The noteworthy data regarding Grind 5 is the relatively high wet film light scattering, which is $5.3 \%$ higher than the standard Grind 1. It is doubtful that this higher than expected value is due to a remarkable pigment dispersion state after only five minutes of grind. The most likely reason for the value is sampling error. It is possible that the Grind 5 
formulation received slightly more $\mathrm{TiO}_{2}$ than the other formulations due to inherent variability in pigment addition and measurement execution. The dry film relative light scattering is not a high value because Grind 5 does not have the air contribution that is present in the other formulations. Adding the diatomaceous earth at the end of the grind, Grind 2, did not make a difference with regards to spread rate or sheen, but there was slightly more air contribution than Grind 1 and significantly more than the other grind time variations. It was concluded that the grind time will remain at 15 minutes and there may be a slight improvement by adding the diatomaceous earth at the end of the grind step.

\subsubsection{Dispersant Chemistry}

Previous work with the Chemours ${ }^{\circledR}$ flat grade $\mathrm{TiO}_{2}$ has shown that a less hydrophilic, more neutral dispersant (Dispersant C) is more efficient at dispersing the particles than the hydrophilic dispersant (Dispersant A) being used in the previous formulas. Five different dispersants, ranging from hydrophilic (Dispersant A) to hydrophobic (Dispersant E), were used in Formula \#2. The results are shown in Table 11:

Table 11: Data for Formula \#2 Dispersant Variations

\begin{tabular}{|c|c|c|c|c|c|c|c|}
\hline \multirow{2}{*}{ Paint } & \multirow{2}{*}{ KU } & \multirow{2}{*}{ ICI (P) } & \multirow{2}{*}{ Sheen } & $\begin{array}{c}\text { Spread Rate } \\
\left.\mathbf{f f t}^{2} / \mathbf{g a l}\right)\end{array}$ & \multicolumn{3}{|c|}{ Relative Light Scattering } \\
\cline { 5 - 8 } & & & & Wet & Dry & Oiled \\
\hline Dispersant A & 95.4 & 0.946 & 11.2 & 615 & 100 & 100 & 100 \\
Dispersant B & 94.7 & 0.858 & 11.3 & 627 & 99.5 & 103.9 & 103.3 \\
Dispersant C & 95.7 & 0.900 & 11.1 & 644 & 102.7 & 104.5 & 104.2 \\
Dispersant D & 98.8 & 0.888 & 11.0 & 608 & 100.0 & 105.2 & 103.5 \\
Dispersant E & 94.6 & 0.954 & 11.4 & 637 & 102.3 & 107.2 & 108.4 \\
\hline
\end{tabular}

The relative light scattering increased in the dry film as the hydrophobicity of the dispersant increased, but as hypothesized, Dispersant $\mathrm{C}$ gave the highest spread rate. Dispersant $\mathrm{C}$ had the highest wet film hiding, which suggests a good wet film $\mathrm{TiO}_{2}$ 
dispersion, assuming that the $\mathrm{TiO}_{2}$ content for each sample was indeed the same.

Surprisingly, the performance of Dispersant E was not far behind that of Dispersant C.

The hydrophobic dispersant was not expected to perform as well as it did because,

historically, the more neutral dispersants have had better success with the flat grade

pigment being used in this formulation. Nevertheless, Dispersant E created the best dry

film dispersion. However, it did not contain the same amount of air within the film. For

this reason, the spread rate was slightly lower than Dispersant C. Therefore, Formula \#3

was created to replace Dispersant A with Dispersant C, while maintaining the rest of the Formula \#2 ingredients. Formula \#3 is shown in the Appendix.

\subsection{Formula \#3}

\subsubsection{Dispersant Concentration}

In the next set of formulations, variations of Formula \#3 were created with varying concentrations of Dispersant $\mathrm{C}$. The dispersant concentration contained by each variation is displayed in Table 12:

Table 12: Formula \#3 Dispersant Concentration Variations

\begin{tabular}{c|c}
\hline Paint & Dispersant C concentration (\%) \\
\hline Formula \#3 & 0.11 \\
Variation 1 & 0.07 \\
Variation 2 & 0.11 \\
Variation 3 & 0.15 \\
Variation 4 & 0.19 \\
Variation 5 & $0.19+$ No *IPD \\
\hline
\end{tabular}

*Inorganic Particle Dispersant

Note that Variation 5 has the same Dispersant $\mathrm{C}$ concentration as Variation 4, but it does not contain any amount of inorganic particle dispersant. Likewise, Variation 2 is identical to Formula \#3, with Formula \#3 being used as a control. The results are displayed in Table 13: 
Table 13: Data for Formula \#3 Dispersant Concentration Variations

\begin{tabular}{|c|c|c|c|c|c|c|c|}
\hline \multirow{2}{*}{ Paint } & \multirow{2}{*}{ KU } & \multirow{2}{*}{ ICI (P) } & \multirow{2}{*}{ Sheen } & $\begin{array}{c}\text { Spread Rate } \\
\mathbf{f f t}^{\mathbf{2}} \text { /gal) }\end{array}$ & \multicolumn{3}{|c|}{ Relative Light Scattering } \\
\cline { 6 - 8 } & & & Wet & Dry & Oiled \\
\hline Formula \#3 & 95.7 & 0.900 & 11.1 & 644 & 100 & 100 & 100 \\
Variation 1 & 96.7 & 0.913 & 11.0 & 639 & 100.7 & 96.6 & 92.1 \\
Variation 2 & 97.4 & 0.992 & 11.1 & 642 & 98.1 & 97.2 & 95.9 \\
Variation 3 & 96.4 & 0.937 & 11.2 & 615 & 98.7 & 96.0 & 95.0 \\
Variation 4 & 97.1 & 0.908 & 11.1 & 630 & 98.7 & 95.4 & 95.2 \\
Variation 5 & 101.8 & 0.896 & 11.8 & 636 & 99.9 & 96.6 & 93.1 \\
\hline
\end{tabular}

The Dispersant C variations were not dramatically different from each other. Variation 5 did not contain any of the inorganic particle dispersant, which resulted in the highest sheen. Formulating without the inorganic dispersant was of interest because it is rarely used in North America in an interior architectural latex paint unless it contains zinc oxide or a similar inorganic particle. Formula \#3 and Variation 2 are identical, and resulted in the highest spread rate, although there was some variation among the relative light scattering values. Formula \#3 had the least amount of hiding due to air contribution, which could be a characteristic of batch to batch variability since Formula \#3 was created on a previous day. The combination of having the highest spread rate and best hiding power suggests that the Dispersant $\mathrm{C}$ concentration already being used in Formula \#3 is optimum.

\subsubsection{Pigment and Dispersant Combinations}

In the next set of paints, different $\mathrm{TiO}_{2}$ products were tested with different dispersants. The combinations are summarized in Table 14: 
Table 14: Pigment and Dispersant Variations

\begin{tabular}{c|c|c}
\hline Paint & TiO $_{2}$ & Dispersant \\
\hline Formula \#2 & Chemours® Flat Grade 1 & Dispersant A \\
Formula \#3 & Chemours® Flat Grade 1 & Dispersant C \\
Variation 1 & Chemours® Flat Grade 2 & Dispersant A \\
Variation 2 & Chemours® Flat Grade 2 & Dispersant C \\
Variation 3 & Competitor Flat Grade & Dispersant A \\
Variation 4 & Competitor Flat Grade & Dispersant C \\
\hline
\end{tabular}

The pigments tested were a Chemours ${ }^{\circledR}$ flat grade pigment (Chemours ${ }^{\circledR}$ Flat

Grade 1), which has been used in all of the formulations thus far, an older Chemours ${ }^{\circledR}$

flat grade pigment (Chemours ${ }^{\circledR}$ Flat Grade 2), and a competitor flat grade pigment. Each pigment was tested with Dispersant A and Dispersant C. The results of the measurements are shown in Table 15:

Table 15: Data for Pigment and Dispersant Variations

\begin{tabular}{|c|c|c|c|c|c|c|c|}
\hline \multirow{2}{*}{ Paint } & \multirow{2}{*}{ KU } & \multirow{2}{*}{ ICI (P) } & \multirow{2}{*}{ Sheen } & \multirow{2}{*}{$\begin{array}{c}\text { Spread Rate } \\
\left.\mathbf{f f t}^{\mathbf{2}} \text { /gal }\right)\end{array}$} & \multicolumn{2}{|c|}{ Relative Light Scattering } \\
\cline { 6 - 8 } & & & & 640 & 100 & 100 & 100 \\
Formula \#2 & 96.7 & 0.913 & 11.3 & 716 & 103.2 & 107.6 & 95.6 \\
Formula \#3 & 98.1 & 0.929 & 11.0 & 684 & 94.6 & 99.6 & 93.7 \\
Variation 1 & 95.0 & 0.908 & 10.8 & 624 & 86.1 & 93.2 & 93.1 \\
Variation 2 & 96.0 & 0.888 & 10.4 & 624 & 94.3 & 87.4 & 92.0 \\
Variation 3 & 95.9 & 0.979 & 9.7 & 612 & 92.5 & 85.5 & 85.7 \\
Variation 4 & 96.1 & 0.904 & 9.8 & 585 & & & \\
\hline
\end{tabular}

Not surprisingly, Formula \#3 gave the highest spread rate. As mentioned earlier, Dispersant C has historically worked well with Chemours ${ }^{\circledR}$ Flat Grade 1. Variation 1, containing Dispersant A and Chemours ${ }^{\circledR}$ Flat Grade 2 gave the second highest spread rate. Like Formula \#3, Dispersant A has been proven to be a great dispersant for that pigment. The Competitor Flat Grade formulations proved to have the worst performance with both of the dispersants, although, they did have the lowest sheen values. The high sheen measurements associated with Formula \#3 must be caused by the pigment diminishing the diffuse light scattering of the film. Inferior surface roughness could be to 
blame for the lack of diffuse reflection. Nevertheless, Formula \#3 has a superior spread rate due to its pigment dispersion efficiency and air void formation.

\subsubsection{Formula \#3 Variability}

One observation worth noting is how much higher the spread rate is for this trial compared to the previous one. The spread rate and light scattering values of both trials are compared in Table 16:

Table 16: Formula \#3 Comparison

\begin{tabular}{|c|c|c|c|c|}
\hline \multirow{2}{*}{ Paint } & Spread Rate & \multicolumn{3}{|c|}{ Relative Light Scattering } \\
\cline { 3 - 5 } & $\left(\mathbf{f t}^{\mathbf{2}}\right.$ /gal) & Wet & Dry & Oiled \\
\hline Formula \#3 & 644 & 100 & 100 & 100 \\
Formula \#3 & 716 & 105.8 & 107.0 & 105.9 \\
\hline
\end{tabular}

The spread rate of the second trial was $72 \mathrm{ft}^{2} / \mathrm{gal}$ higher than the first trial while the relative light scattering yielded a 5.8\% increase in efficiency. Therefore, the disparity in hiding power between these two identical paints is most likely due to dispersion quality, assuming with confidence that equal amounts of pigment were added to the formulations.

\subsubsection{Latex Chemistry}

Formula \#3 was formulated with a variety of resin chemistries and particle sizes. A summary of the latexes used in the variations are summarized in Table 17:

Table 17: Formula \#3 Latex Variations

\begin{tabular}{c|c|c}
\hline Paint & Latex Chemistry & Average Particle Size \\
\hline Latex A & Vinyl Acrylic & $100-200 \mathrm{~nm}$ \\
Latex B & All Acrylic & $130 \mu \mathrm{m}$ \\
Latex C & All Acrylic & $100 \mathrm{~nm}$ \\
Latex D & All Acrylic & $150 \mathrm{~nm}$ \\
Latex E & Vinyl Acetate/Ethylene + Protective Colloid & $225 \mathrm{~nm}$ \\
Latex F & Vinyl Acetate/Ethylene & $150-190 \mu \mathrm{m}$ \\
\hline
\end{tabular}


Data comparison of the different resin chemistries and particle sizes are shown in

Table 18:

Table 18: Data for Formula \#3 Latex Variations

\begin{tabular}{|c|c|c|c|c|c|c|c|}
\hline \multirow{2}{*}{ Paint } & \multirow{2}{*}{ KU } & \multirow{2}{*}{ ICI (P) } & \multirow{2}{*}{ Sheen } & $\begin{array}{c}\text { Spread Rate } \\
\left(\mathbf{f t}^{\mathbf{2}} / \mathbf{g a l}\right)\end{array}$ & \multicolumn{3}{|c|}{ Relative Light Scattering } \\
\cline { 5 - 8 } & & & & 716 & 100 & 100 & 100 \\
Latex A & 98.1 & 0.929 & 11.0 & 605 & 100.7 & 83.5 & 99.4 \\
Latex B & 121.0 & 0.979 & 8.5 & 576 & 98.9 & 80.9 & 94.6 \\
Latex C & 133.0 & 1.258 & 8.9 & 5.9 & 97.3 & 77.2 & 93.5 \\
Latex D & 120.3 & 0.904 & 8.5 & 568 & 93.4 & 85.6 & 96.6 \\
Latex E & 99.8 & 0.900 & 10.5 & 601 & 95.5 & 85.1 & 97.9 \\
Latex F & 101.1 & 0.875 & 9.8 & 615 & & \\
\hline
\end{tabular}

Latex A is clearly the best option from the list and happens to be the one that has been used in all of the previous formulations. The vinyl acrylic latex allows for an efficient dispersion of the $\mathrm{TiO}_{2}$ particles creating the best hiding power with close to ideal high and low shear viscosity. Latex A also had the highest amount of air in the system, although it had the highest sheen value.

\subsubsection{Associative Thickener Effects}

The three paints from above with high KU values (Latex B, C, and D) were reformulated without any hydrophobically-modified, alkali swellable emulsion (HASE), which acts as the KU builder, in order to observe the viscosity decrease and its effect on spread rate. The results of the paints with and without the associative thickener are shown in Tables 19, 20, and 21:

Table 19: Data for Latex B With and Without Associative Thickener

\begin{tabular}{|c|c|c|c|c|c|c|c|}
\hline \multirow{2}{*}{ Paint } & \multirow{2}{*}{ KU } & \multirow{2}{*}{ ICI (P) } & \multirow{2}{*}{ Sheen } & $\begin{array}{c}\text { Spread Rate } \\
\left(\mathbf{f t}^{\mathbf{2}} / \mathbf{g a l}\right)\end{array}$ & \multicolumn{3}{|c|}{ Relative Light Scattering } \\
\cline { 6 - 8 } & & & & Wet & Dry & Oiled \\
\hline With HASE & 121.0 & 0.979 & 8.5 & 605 & 100 & 100 & 100 \\
No HASE & 112.2 & 0.896 & 8.7 & 572 & 99.8 & 100 & 95.1 \\
\hline
\end{tabular}


Table 20: Data for Latex C With and Without Associative Thickener

\begin{tabular}{|c|c|c|c|c|c|c|c|}
\hline \multirow{2}{*}{ Paint } & \multirow{2}{*}{ KU } & \multirow{2}{*}{ ICI (P) } & \multirow{2}{*}{ Sheen } & $\begin{array}{c}\text { Spread Rate } \\
\left(\mathbf{f t}^{\mathbf{2}} / \mathbf{g a l}\right)\end{array}$ & \multicolumn{3}{|c|}{ Relative Light Scattering } \\
\cline { 5 - 8 } & & & & Wet & Dry & Oiled \\
\hline With HASE & 133.0 & 1.258 & 8.9 & 576 & 100 & 100 & 100 \\
No HASE & 106.2 & 0.946 & 9.2 & 528 & 98.6 & 99.8 & 98.0 \\
\hline
\end{tabular}

Table 21: Data for Latex D With and Without Associative Thickener

\begin{tabular}{|c|c|c|c|c|c|c|c|}
\hline \multirow{2}{*}{ Paint } & \multirow{2}{*}{ KU } & \multirow{2}{*}{ ICI (P) } & \multirow{2}{*}{ Sheen } & $\begin{array}{c}\text { Spread Rate } \\
\left(\mathbf{f t}^{2} / \mathbf{g a l}\right)\end{array}$ & \multicolumn{3}{|c|}{ Relative Light Scattering } \\
\cline { 5 - 8 } & & & & Wet & Dry & Oiled \\
\hline With HASE & 120.3 & 0.904 & 8.5 & 568 & 100 & 100 & 100 \\
No HASE & 99.4 & 0.750 & 8.9 & 528 & 96.0 & 99.7 & 104.2 \\
\hline
\end{tabular}

The decrease in spread rate correlated with the decrease in low shear rate viscosity. The results are due to these latexes being all acrylic and their particle size. The smaller, all acrylic particles interact with the hydrophobic moieties of the hydrophobically-modified thickener molecules, resulting in the high viscosity. Taking out the hydrophobically-modified thickener resulted in a viscosity decrease. Latex B did not see as drastic of a decrease in viscosity as Latex C and D did, and therefore the spread rate was not affected as much as the latter two latex formulations. Latex $\mathrm{C}$ saw the greatest decrease in viscosity with Latex D close behind. This trend continued with regard to the spread rate data where Latex $\mathrm{C}$ had the greatest decrease followed by Latex C and Latex B saw the least change. As the paint viscosity decreases, fewer solids get deposited onto the substrate leading to diminished hiding power and, ultimately, a lower spread rate.

\subsection{Formula \#4}

At this point, a new formula was obtained (Formula \#4), which contains the same components as Formula \#2, but includes a silica-deficient, sodium-potassium alumina 
silicate filler as an additional ingredient. Formula \#4 is shown in the Appendix. Note that this formula includes Dispersant A rather than Dispersant C.

\subsubsection{Formula \#2 Comparison}

Data collected after generation of Formula \#4 was compared to that of Formula \#2 and is shown in Table 22:

Table 22: Data for Formula \#4 Comparison

\begin{tabular}{|c|c|c|c|c|c|c|c|}
\hline \multirow{2}{*}{ Paint } & \multirow{2}{*}{ KU } & \multirow{2}{*}{ ICI (P) } & \multirow{2}{*}{ Sheen } & $\begin{array}{c}\text { Spread Rate } \\
\left(\mathbf{f t}^{\mathbf{2}} / \mathbf{g a l}\right)\end{array}$ & \multicolumn{3}{|c|}{ Relative Light Scattering } \\
\cline { 6 - 8 } & & & & 615 & 100 & 100 & 100 \\
\hline Formula \#2 & 95.4 & 0.946 & 11.2 & 615 & Wet & Dry & Oiled \\
Formula \#4 & 95.9 & 1.025 & 4.8 & 605 & 98.4 & 92.7 & 91.3 \\
\hline
\end{tabular}

The viscosities and spread rates for both formulations were very similar. The light scattering for the dry Formula \#4 film was significantly lower than Formula \#2 even though the wet film light scattering was comparable. Formula \#4 does have a fraction lower pigment concentration due to the new extender addition, but the large decrease in hiding suggests that the pigment particles are agglomerating upon film formation, which must be a result of the alumina silicate addition. The most noteworthy observation from this data set is the extremely low sheen value created with Formula \#4, which meets the project's goal of attaining a sheen value equaling less than 5.0.

\subsection{Formula \#5}

Yet another paint formulation was obtained, which will be referred to as Formula \#5 and is displayed in the Appendix. Formula \#5 contains the same ingredients as Formula \#4, but a Chemours ${ }^{\circledR}$ universal grade $\mathrm{TiO}_{2}$ pigment was added to increase the $\mathrm{TiO}_{2}$ content. 


\subsubsection{Formula \#4 Comparison}

The characteristics of Formula \#4 and Formula \#5 were compared in Table 23:

Table 23: Data for Formula \#5 Comparison

\begin{tabular}{|c|c|c|c|c|c|c|c|}
\hline \multirow{2}{*}{ Paint } & \multirow{2}{*}{ KU } & \multirow{2}{*}{ ICI (P) } & \multirow{2}{*}{ Sheen } & $\begin{array}{c}\text { Spread Rate } \\
\left(\mathbf{f t}^{\mathbf{2}} / \mathbf{g a l}\right)\end{array}$ & \multicolumn{3}{|c|}{ Relative Light Scattering } \\
\cline { 6 - 8 } & & & & Wet & Dry & Oiled \\
\hline Formula \#4 & 95.9 & 1.025 & 4.8 & 605 & 100 & 100 & 100 \\
Formula \#5 & 99.5 & 1.137 & 6.1 & 769 & 112.0 & 125.4 & 121.7 \\
\hline
\end{tabular}

Due to the added pigment, the light scattering of Formula \#5 was greatly

increased, which led to a much higher spread rate compared to Formula \#4. The increased spread rate is partially due to the added air contribution obtained by Formula \#5. The increased KU viscosity may have aided by adding to the film build. Although the spread rate gained a drastic improvement, the sheen value increased slightly, to a point that does not satisfy the project's goal.

\subsubsection{Dispersant Chemistry}

Formula \#5 was formulated with the same five dispersants (Dispersants A-E) as previously used. The KU, ICI, and sheen for each paint was very similar (100 KU, 1.13 $\mathrm{P}$, and 6.1). Spread rate data was collected in triplicate for each of the five paints and is summarized in Table 24:

Table 24: Averaged Data for Formula \#5 Dispersant Variation Triplicates

\begin{tabular}{cccc}
\hline Paint & $\begin{array}{c}\text { Avg. Spread Rate } \\
\left(\mathbf{f t}^{2} / \mathbf{g a l}\right)\end{array}$ & $\begin{array}{c}\text { Avg. Rel. Spread Rate } \\
\left(\mathbf{f t}^{\mathbf{2}} / \mathbf{g a l}\right)\end{array}$ & $\begin{array}{c}\text { Avg. Rel. Air } \\
\text { Contribution }\end{array}$ \\
\hline Dispersant A & 780 & 0 & 0 \\
Dispersant B & 766 & -14 & -0.7 \\
Dispersant C & 755 & -25 & -2.2 \\
Dispersant D & 749 & -30 & -0.9 \\
Dispersant E & 746 & -34 & -2.1 \\
\hline
\end{tabular}

The average spread rate is the the mean spread rate of the triplicate trials. The average relative spread rate is the difference between the average spread rate of the given 
dispersant relative to the average spread rate of Dispersant A. The average relative air contribution was calculated by subtracting the relative light scattering value of the oiled film from the relative light scattering value of the dry film for each trial of the triplicate. This calculation results in the hiding power created by air contribution, which is then averaged for the triplicate to yield the average relative air contribution shown in the third column of Table 24 .

It is clear that Dispersant A is the superior product for this formulation because it yielded the highest spread rate. One reason for its success is its ability to create a film that is rich in air voids with at least $0.7 \%$ more air than the other paints. The increased air presence alone is not enough to account for the superb spread rate. This hydrophilic dispersant is creating the most optimum pigment dispersion by interacting with the pigment surface just enough to space the particles efficiently.

\subsubsection{Formula \#5 Variability}

Formula \#5 was formulated in triplicate. Viscosity, gloss, spread rate, and relative light scattering data was collected to examine for variability and is shown in the bottom three rows of Table 25:

Table 25: Data for Formula \#5 Replicates

\begin{tabular}{|c|c|c|c|c|c|c|c|}
\hline \multirow{2}{*}{ Paint } & \multirow{2}{*}{ KU } & \multirow{2}{*}{ ICI (P) } & \multirow{2}{*}{ Sheen } & $\begin{array}{c}\text { Spread Rate } \\
\text { (ft } \mathbf{2} \text { /gal })\end{array}$ & \multicolumn{2}{|c|}{ Relative Light Scattering } \\
\cline { 6 - 8 } & & & & Wet & Dry & Oiled \\
\hline Formula \#5 & 99.6 & 1.233 & 6.0 & 788 & 100 & 100 & 100 \\
Formula \#5 & 99.5 & 1.110 & 6.0 & 762 & 102.5 & 97.6 & 104.2 \\
Formula \#5 & 99.4 & 1.117 & 6.0 & 741 & 107.2 & 101.9 & 105.2 \\
Formula \#5 & 99.4 & 1.117 & 6.0 & 787 & 104.3 & 101.5 & 101.5 \\
\hline
\end{tabular}

A spread rate range of $46 \mathrm{ft}^{2} /$ gal was observed for the triplicate while the rest of the properties were nearly identical. Another investigator replicated Formula \#5 and performed the spread rate procedure. The second investigator measured a spread rate of 
$880 \mathrm{ft}^{2} / \mathrm{gal}$, which is drastically higher than the values obtained by the primary

investigator. The primary investigator performed spread rate analysis on the paint sample formulated by the second investigator, resulting in the data shown in the top row of Table 25. All of the values were very similar to the primary investigator's previous data, shown in the bottom three rows, which suggests that all of the paints were nearly identical. However, the spread rate value of the second investigator's formulation collected by the primary investigator was $92 \mathrm{ft}^{2} / \mathrm{gal}$ lower than the spread rate value obtained by the second investigator who measured the same paint sample. Clearly, there was a fundamental difference between the procedures used by both investigators that yielded such a great difference in spread rate. The noteworthy deviation between their procedures was the vacuum plate used to carry out the weighed drawdowns. When the primary investigator noticed this discontinuity, the four Formula \#5 paints were gathered and spread rate analysis was conducted on the vacuum plate used by the second investigator. The data set from this analysis is shown in Table 26 where the values obtained by the second investigator's formulation are located on the top row:

Table 26: Data for Formula \#5 Collected on Second Vacuum Plate

\begin{tabular}{|c|c|c|c|c|}
\hline \multirow{2}{*}{ Paint } & Spread Rate & \multicolumn{3}{|c|}{ Relative Light Scattering } \\
\cline { 3 - 5 } & $\left(\mathbf{f t}^{\mathbf{2}}\right.$ /gal) & Wet & Dry & Oiled \\
\hline Formula \#5 & 884 & 100 & 100 & 100 \\
Formula \#5 & 799 & 92.5 & 95.0 & 103.8 \\
Formula \#5 & 821 & 98.8 & 96.0 & 103.0 \\
Formula \#5 & 884 & 97.4 & 99.5 & 104.5 \\
\hline
\end{tabular}

Obviously the vacuum plate used by the second investigator yields higher spread rate results than the vacuum plate that the primary investigator has used in all previous trials. The difference is the amount of paint that is deposited onto the substrate. 
Somehow, the new machine allows for more paint to be applied onto the opacity chart. Theoretically, the spread rate calculation should account for the difference as more paint means greater hiding, but it clearly is not a direct correlation.

\subsection{Spread Rate Method Variability}

This brings up the point of variability within the testing method. Figure 12 gives an example of an opacity chart's light reflectance readings:

\begin{tabular}{|c|}
\hline Y Value \\
\hline 91.318 \\
\hline 85.182 \\
\hline 90.518 \\
\hline 83.691 \\
\hline
\end{tabular}

Figure 12: Example of opacity chart light reflectance readings used for spread rate.

Due to the rheology of the paint, the reflectance value is always greater on the upper panels. The shear rate applied by the drawdown blade causes the paint to shearthin. The shear-thinning effect causes less of the paint to be deposited at the bottom of the chart compared to the top. Therefore, a thinner film, with diminished light scattering efficiency, is created as the drawdown is performed. Variation of the spread rate values for Formula \#5 due to the shear-thinning effect is shown in Table 27:

Table 27: Formula \#5 Data Showing Chart Variability

\begin{tabular}{|c|c|c|c|c|}
\hline \multirow{2}{*}{ Sample } & Spread Rate & \multicolumn{3}{|c|}{ Relative Light Scattering } \\
\cline { 3 - 5 } & $\left(\mathbf{f t}^{2} / \mathbf{g a l}\right)$ & Wet & Dry & Oiled \\
\hline All & 762 & 100 & 100 & 100 \\
Top & 794 & 106.8 & 107.9 & 108.1 \\
Bottom & 728 & 93.9 & 92.3 & 92.2 \\
\hline
\end{tabular}


If just the top white and black panels were used for the spread rate calculation of one of the Formula \#5 paints, the results would be as shown in the middle row. The normal data analysis method, which averages both pairs of panels, is shown in the top row. The bottom panels were used to measure the spread rate shown in the bottom row. Which panels are used for spread rate calculation clearly alters the output value. The hiding power due to air contribution does not change no matter which panels are used for the spread rate calculation. Therefore, it is the amount of pigment being deposited onto the substrate that is responsible for the inconsistency.

\subsubsection{Chart Comparison}

It was hypothesized that a shorter opacity chart would combat the film thickness variation. The same spread rate procedure, using Formula \#5, was performed on a N2A-2 Leneta Opacity chart, which contains only one black and one white tile. The results from the analysis were compared to that obtained from the long opacity charts and are summarized in Table 28:

Table 28: Formula \#5 Long vs. Short Opacity Chart

\begin{tabular}{|c|c|c|c|c|c|c|c|}
\hline \multirow{2}{*}{ Paint } & \multirow{2}{*}{ KU } & \multirow{2}{*}{ ICI (P) } & \multirow{2}{*}{ Sheen } & $\begin{array}{c}\text { Spread Rate } \\
\left(\mathbf{f t}^{\mathbf{2}} \mathbf{/ g a l}\right)\end{array}$ & \multicolumn{3}{|c|}{ Relative Light Scattering } \\
\cline { 6 - 8 } & & & & Wet & Dry & Oiled \\
\hline Long Chart & 99.4 & 1.117 & 6.0 & 759 & 100 & 100 & 100 \\
Short Chart & 99.4 & 1.117 & 6.0 & 768 & 100.4 & 102.4 & 101.3 \\
\hline
\end{tabular}

There was a slightly greater amount of air contribution associated with the short chart, which could be responsible for the larger spread rate. Regardless, the comparison between the long and short opacity charts provided extremely similar values and only slight spread rate deviation. 
In order to determine if the short chart reduces spread rate variability, the spread rate procedure was performed in triplicate with Formula \#5. The results from the replication are shown in Table 29:

Table 29: Spread Rate Precision on Short Opacity Chart

\begin{tabular}{|c|c|c|c|c|c|c|c|}
\hline \multirow{2}{*}{ Paint } & \multirow{2}{*}{ KU } & \multirow{2}{*}{ ICI (P) } & \multirow{2}{*}{ Sheen } & $\begin{array}{c}\text { Spread Rate } \\
\left.\mathbf{f f t}^{\mathbf{2}} \text { /gal }\right)\end{array}$ & \multicolumn{3}{|c|}{ Relative Light Scattering } \\
\cline { 6 - 8 } & & & & Wet & Dry & Oiled \\
\hline Formula \#5 & 99.5 & 1.110 & 6.0 & 767 & 100 & 100 & 100 \\
Formula \#5 & 99.4 & 1.117 & 6.0 & 761 & 99.7 & 99.8 & 100.2 \\
Formula \#5 & 99.4 & 1.117 & 6.0 & 768 & 100.4 & 100.7 & 99.9 \\
\hline
\end{tabular}

Clearly, the short opacity charts result in more precise spread rate calculations relative to the long chart data shown previously in Table 25 . The short charts give more consistent reflectance values because the shear thinning effect isn't as problematic on the shorter charts. Therefore, the reflectance readings are more consistent because the film thickness is more uniform throughout the drawdown area.

\subsection{Formula \#6}

At this point, achieving a lower sheen value was of utmost importance since the spread rate for Formula \#5 was well above $600 \mathrm{ft}^{2} / \mathrm{gal}$ and pushing $800 \mathrm{ft}^{2} / \mathrm{gal}$, but the sheen was not below the threshold. Formula \#6 was created in order to decrease the sheen and is presented in the Appendix. This formulation is similar to Formulation \#5, but has one key difference that was thought would help lower the sheen. A new structured kaolin clay product was introduced that has a particle size that just over half that of the clay it replaced. The greater surface area in the new clay increased the oil absorption (OA) value from 15 to $120 \mathrm{~g} / 100 \mathrm{~g}$, which drastically lowered the CPVC. Formula \#5 and \#6 spread rate and light scattering data is shown in Table 30: 
Table 30: Data for Formula \#6 Comparison

\begin{tabular}{|c|c|c|c|c|c|c|c|}
\hline \multirow{2}{*}{ Paint } & \multirow{2}{*}{ KU } & \multirow{2}{*}{ ICI (P) } & \multirow{2}{*}{ Sheen } & $\begin{array}{c}\text { Spread Rate } \\
\left(\mathbf{f t}^{\mathbf{2}} \text { /gal) }\right.\end{array}$ & \multicolumn{3}{|c|}{ Relative Light Scattering } \\
\cline { 6 - 8 } & & & & Wet & Dry & Oiled \\
\hline Formula \#5 & 99.6 & 1.117 & 6.0 & 766 & 100 & 100 & 100 \\
Formula \#6 & 101.0 & 1.310 & 8.3 & 768 & 102.5 & 102.3 & 113.4 \\
\hline
\end{tabular}

The new kaolin clay had the reverse effect than was anticipated. The sheen value increased to 8.3 , while the spread rate wasn't altered by the change in extender. The lack of spread rate differential is due to a slightly higher $\mathrm{TiO}_{2}$ content in Formula \#6 that is offset by the significantly larger air contribution in Formula \#5. With such a high binder demand, it is surprising that the new, small particle, high surface area clay did not help flatten the paint as well as the previous product. The particle's high OA value was expected to lower the CPVC, which should have yielded more air voids and a rougher surface. However, it is possible that the large alumina silicate and diatomaceous earth particles created a slight amount of gloss in this paint that is well above the CPVC. The somewhat flat top layer created by the filler particles could be the culprit for the increased sheen value seen in Formula \#6. Therefore, the original kaolin clay was used in the next formulation.

\subsection{Formula \#7}

Formula \#7 is the same as Formula \#5, but it incorporates a different diatomaceous earth and the universal grade $\mathrm{TiO} 2$ was entirely removed and partially replaced with additional flat grade pigment. The specifics of Formula \#7 can be seen in the Appendix. Comparison of Formula \#5 and \#7 is shown in Table 31:

Table 31: Data for Formula \#7 Comparison

\begin{tabular}{|c|c|c|c|c|c|c|c|}
\hline \multirow{2}{*}{ Paint } & \multirow{2}{*}{ KU } & \multirow{2}{*}{ ICI (P) } & \multirow{2}{*}{ Sheen } & \multirow{2}{*}{$\begin{array}{c}\text { Spread Rate } \\
\left(\mathbf{f t}^{\mathbf{2}} / \mathbf{g a l}\right)\end{array}$} & \multicolumn{3}{|c|}{ Relative Light Scattering } \\
\cline { 6 - 8 } & & & & Wet & Dry & Oiled \\
\hline Formula \#5 & 99.6 & 1.117 & 6.0 & 766 & 100 & 100 & 100 \\
Formula \#7 & 99.4 & 1.081 & 3.0 & 556 & 94.8 & 82.2 & 89.4 \\
\hline
\end{tabular}


Removal of the universal grade $\mathrm{TiO}_{2}$, in addition to the switch to a slightly larger diatomaceous earth product with a higher OA value, significantly decreased the sheen of the paint sample. The spread rate was sacrificed in order to flatten the paint because of the partial replacement of the universal grade pigment with flat grade $\mathrm{TiO}_{2}$. The change in pigment grade and quantity, in conjunction with the change in diatomaceous earth, resulted in hiding power loss due to lack of air contribution. Since achieving such a low sheen value is now the primary goal, a diminished spread rate is not a critical issue at this juncture. Additional pigment could be added in order to boost the spread rate, but this may threaten the goal of achieving the sheen value obtained by Formula \#7.

\subsection{Formula \#8}

\subsubsection{Formula \#7 Comparison}

An attempt at decreasing the sheen below 3.0 included a slight amount of pigment removal, replacement of the $\mathrm{CaCO}_{3}$ with a different calcined alumina silicate, and introduction of a hydrophobically-modified, ethoxylated urethane (HEUR) thickener to act as a high shear rate builder, resulting in Formula \#8. The Appendix shows the formulation specifics, while Formula \#7 is compared to the new formula in Table 32:

Table 32: Data for Formula \#8 Comparison

\begin{tabular}{|c|c|c|c|c|c|c|c|}
\hline \multirow{2}{*}{ Paint } & \multirow{2}{*}{ KU } & \multirow{2}{*}{ ICI (P) } & Sheen & $\begin{array}{c}\text { Spread Rate } \\
\left(\mathbf{f t}^{2} / \text { gal }\right)\end{array}$ & \multicolumn{3}{|c|}{ Relative Light Scattering } \\
\cline { 6 - 8 } & & & Wet & Dry & Oiled \\
\hline Formula \#7 & 99.4 & 1.081 & 3.0 & 556 & 100 & 100 & 100 \\
Formula \#8 & 100.1 & 1.154 & 2.7 & 543 & 100.9 & 98.7 & 107.7 \\
\hline
\end{tabular}

The combination of changes that led to the development of Formula \#8 achieved a sheen value of 2.7. Removal of the $\mathrm{CaCO}_{3}$ particles and replacement by alumina silicate may have contributed to the diminished sheen, but it is difficult to ignore the affect that $\mathrm{TiO}_{2}$ removal has on sheen. Formula \#5 had a sheen value of 6.0 and a higher $\mathrm{TiO}_{2}$ 
content than Formula \#7 and \#8. When the pigment concentration was dropped by 7\% in Formula \#7, the sheen flattened to 3.0. Another $4 \%$ drop in $\mathrm{TiO}_{2}$ resulted in a sheen value of 2.7 for Formula \#8. The data suggests that removal of the pigment and replacement by extender is the driving force behind sheen reduction. It is difficult to determine the role that the rheology modifiers have when it comes to sheen development.

\subsubsection{Rheology Modifier Chemistry}

Optimization of the pigment with the extender particles and rheology modifiers is crucial when attempting to achieve lofty paint standards such as the ones set forth at the beginning of this project. With that in mind, a series of Formula \#8 variations were made with different thickener and dispersant chemistries in order to better understand their affect on spread rate and sheen development. The variations are summarized in Table 33:

Table 33: Formula \#8 Variations

\begin{tabular}{ccc}
\hline Paint & Thickener & Dispersant \\
\hline $\mathbf{1}$ & High Shear HEUR & Hydrophilic \\
$\mathbf{2}$ & High Shear HEUR & Neutral \\
$\mathbf{3}$ & High Shear HEUR & Hydrophobic \\
$\mathbf{4}$ & Low Shear HEUR & Hydrophilic \\
$\mathbf{5}$ & Low Shear HEUR & Neutral \\
$\mathbf{6}$ & Low Shear HEUR & Hydrophobic \\
$\mathbf{7}$ & High Shear HASE & Hydrophilic \\
$\mathbf{8}$ & High Shear HASE & Neutral \\
$\mathbf{9}$ & High Shear HASE & Hydrophobic \\
$\mathbf{1 0}$ & Low Shear HASE & Hydrophilic \\
$\mathbf{1 1}$ & Low Shear HASE & Neutral \\
$\mathbf{1 2}$ & Low Shear HASE & Hydrophobic \\
\hline
\end{tabular}

Four commercial thickeners were chosen for this study based on their chemistry and performance. The HEUR thickener from Formula \#8 was formulated into variation paints $1-3$ and acted as a high shear rate builder. Another HEUR thickener was formulated into variation paints $4-6$ and acted as a low shear rate builder. The second 
thickener chemistry chosen was that of the hydrophobically-modified, alkali-swellable emulsion (HASE) type thickener. A high shear rate building HASE was used in variation paints $7-9$, while the same low shear rate building HASE used in all of the previous formulations was formulated into variation paints $10-12$. Each of the four thickeners were formulated with a hydrophilic (Dispersant A), neutral (Dispersant C), and a hydrophobic dispersant (Dispersant E), creating the 12 Formula \#8 variation samples.

In order to achieve consistent drawdown film thickness and comparable rheology, all paints were adjusted to $101 \pm 1 \mathrm{KU}$ with their respective HEUR or HASE thickener. After 24 hours, the viscosities had changed to $101 \pm 2 \mathrm{KU}$. Sheen and spread rate analysis was conducted on all of the paints with the data shown in Table 34:

Table 34: Data for Formula \#8 Variations

\begin{tabular}{|c|c|c|c|c|c|}
\hline & & \multirow{2}{*}{ Paint } & Sheen & \multirow{2}{*}{$\begin{array}{c}\text { Spread Rate } \\
\left(\mathbf{f t}^{2} \mathbf{\text { gal }}\right)\end{array}$} & \multicolumn{3}{|c|}{$\begin{array}{c}\text { Relative Light } \\
\text { Scattering }\end{array}$} \\
\cline { 4 - 6 } & & & Wet & Dry & Oiled \\
\hline $\mathbf{1}$ & 2.7 & 565 & 100 & 100 & 100 \\
$\mathbf{2}$ & 2.7 & 561 & 101.6 & 99.8 & 97.1 \\
$\mathbf{3}$ & 2.8 & 556 & 104.6 & 99.7 & 100.1 \\
$\mathbf{4}$ & 2.6 & 539 & 101.8 & 96.7 & 95.9 \\
$\mathbf{5}$ & 2.7 & 560 & 103.3 & 100.4 & 95.9 \\
$\mathbf{6}$ & 2.8 & 567 & 103.9 & 101.0 & 96.2 \\
$\mathbf{7}$ & 2.6 & 550 & 105.0 & 97.4 & 99.0 \\
$\mathbf{8}$ & 2.7 & 564 & 106.1 & 99.7 & 100.8 \\
$\mathbf{9}$ & 2.7 & 531 & 100.3 & 94.2 & 93.3 \\
$\mathbf{1 0}$ & 2.6 & 535 & 108.0 & 94.9 & 88.2 \\
$\mathbf{1 1}$ & 2.7 & 533 & 106.5 & 94.4 & 91.7 \\
$\mathbf{1 2}$ & 2.7 & 538 & 99.9 & 94.1 & 96.0 \\
Formula \#8 & 2.7 & 545 & 103.2 & 97.4 & 94.8 \\
\hline
\end{tabular}

The sheen values were virtually identical for Formula \#8 and all of its variations. This data suggests that the extender package is the main determining factor behind sheen development, and that the rheology modifier and dispersant chemistry plays a less significant role. However, the spread rate and light scattering values were not constant 
throughout the paint variations. The HEUR thickeners outperformed the HASE thickeners with an average spread rate that was $16 \mathrm{ft}^{2} / \mathrm{gal}$ higher. Interestingly, the low shear rate building HASE led to the lowest spread rates. This is the product that has been used in each of the previous formulations. The high shear rate building HEUR, which is new in Formula \#8, yielded the highest spread rate on average. Formula \#8 incorporates both of these thickeners, but its spread rate was below average relative to its 12 variations.

\subsubsection{Rheology}

Low shear rate rheology testing was performed on each of the Formula \#8 variations and is shown in Figure 13:

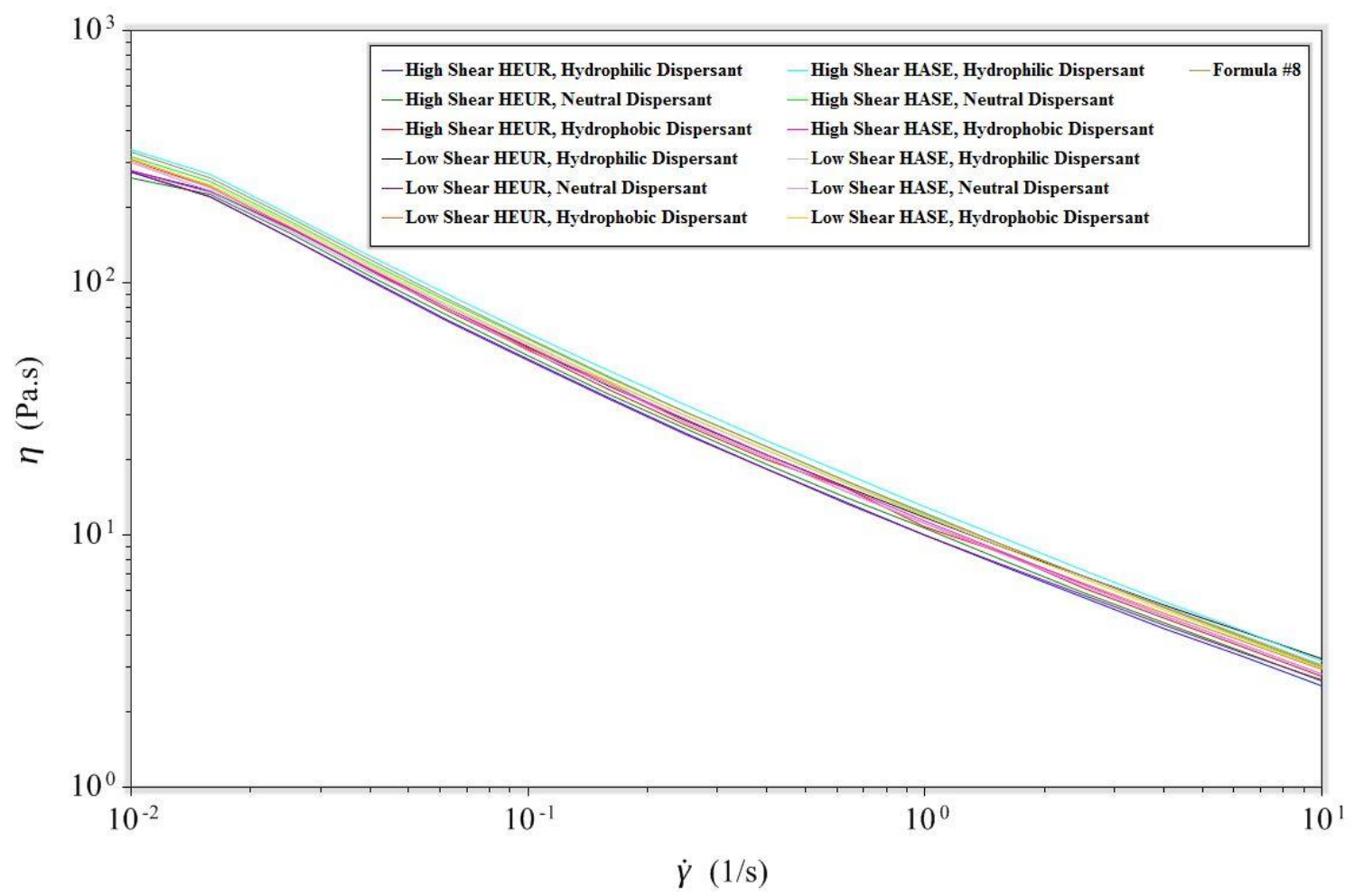

Figure 13: Low shear rate viscosity vs. shear rate curves for Formula \#8 variations. 
The low shear rates depicted in the rheology profile associate with sag and leveling shear forces. Sag and leveling are the primary forces that impact sheen development during the film formation process. The extremely consistent rheology curves of the Formula \#8 variations suggest that the thickener and dispersant chemistry does not greatly affect the low shear rate rheology of these relatively low latex concentration paints. This is a possible reason for why the sheen values were almost identical for Formula \#8 and its variants. It is important to point out that this data does not prove that rheology cannot be used to correlate with sheen development in general. Unfortunately, no correlations can be drawn with regard to spread rate or air contribution as well, due to the consistency.

\subsection{Surface Roughness Images}

\subsubsection{Film Formation}

A Keyence VR-3000 series One-Shot 3D Measuring Macroscope was utilized to quantify surface roughness for sheen correlation in the flat paints. The macroscope allows for easy quantification of surface roughness in accordance with International Organization for Standardization (ISO) method 25178. Images were collected during film formation of Formula \#8. The images are shown in Figures 14, 15, and 16: 


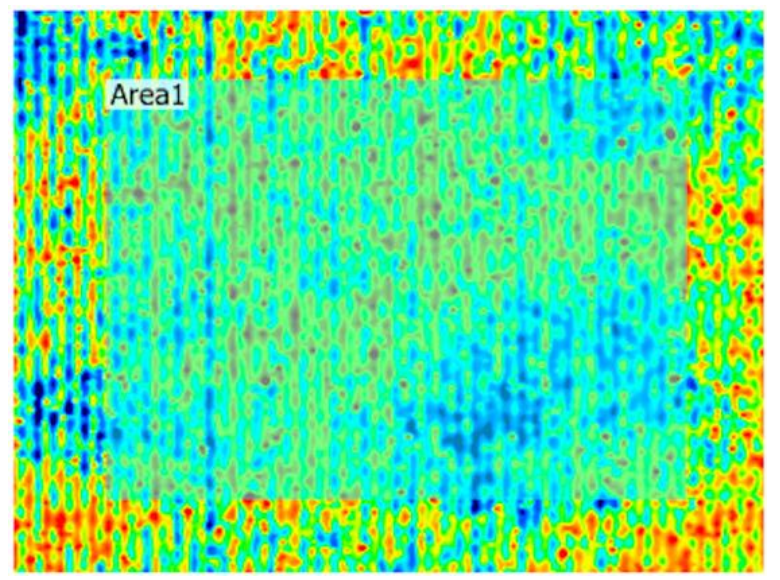

Figure 14: Formula \#8, wet film macroscope image.

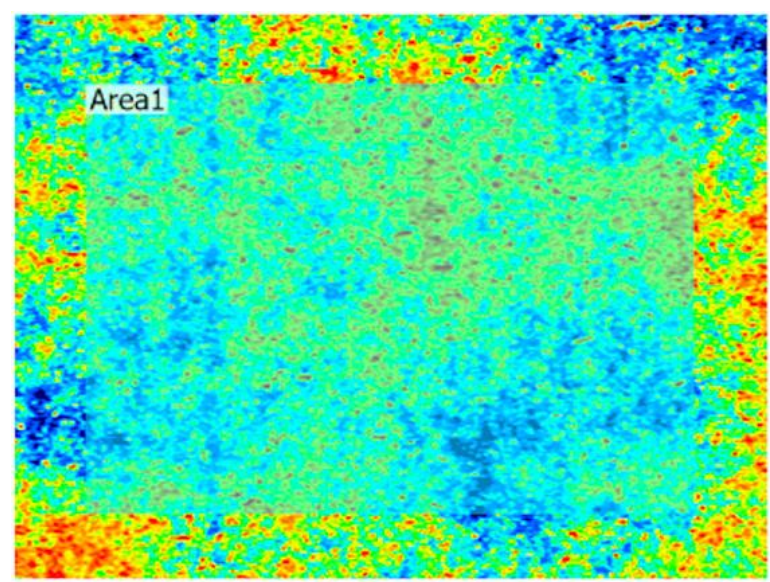

Figure 15: Formula \#8, 5 minute dry film macroscope image.

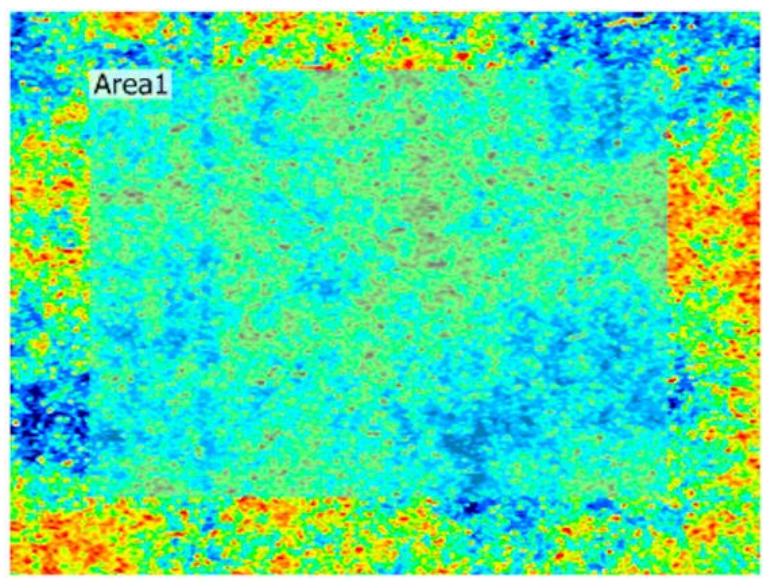

Figure 16: Formula \#8, 10 minute dry film macroscope image. 
Unfortunately, during film evaluation, the Analyzer software left the "Area1" box on all of the macroscope images. Luckily, the images aren't greatly affected by the color change within the "Area1" box, so the discoloration within that area can be ignored. Red portions of the film indicate high peaks while blue areas indicate low valleys of the paint coating. The paint leveling process can be observed by looking between Figure 14 and Figure 15. Immediately following a drawdown, the lines created by the drawdown bar are easily visible in Figure 14. After five minutes, the streaks seem to have disappeared due to the leveling of the paint and there is very little noticeable difference after ten total minutes of drying had elapsed. Quantification of the surface roughness of all three images was conducted by the Analyzer software and is presented in Table 35:

Table 35: Surface Roughness Data for Formula \#8 Film Formation

\begin{tabular}{|c|c|c|c|c|c|c|c|c|}
\hline Paint & $\begin{array}{c}\text { Sq } \\
(\boldsymbol{\mu m})\end{array}$ & Ssk & Sku & $\begin{array}{c}\text { Sp } \\
(\boldsymbol{\mu m})\end{array}$ & $\begin{array}{c}\text { Sv } \\
(\boldsymbol{\mu m})\end{array}$ & $\begin{array}{c}\text { Sz } \\
(\boldsymbol{\mu m})\end{array}$ & $\begin{array}{c}\text { Sa } \\
(\boldsymbol{\mu m})\end{array}$ & $\begin{array}{c}\text { Area } \\
\left(\mathbf{c m}^{2}\right)\end{array}$ \\
\hline Wet & 2.28 & 0.14 & 3.58 & 16.98 & 7.75 & 24.73 & 1.81 & 2.54 \\
5 Minutes & 1.99 & 0.41 & 4.07 & 20.71 & 6.53 & 27.24 & 1.56 & 2.70 \\
10 Minutes & 1.96 & 0.39 & 4.18 & 20.92 & 6.19 & 27.11 & 1.53 & 2.58 \\
\hline
\end{tabular}

The description for each surface roughness value obtained by Analyzer software is displayed in Table 36:

Table 36: Surface Roughness Parameter Descriptions

\begin{tabular}{|c|l|}
\hline Parameter & \multicolumn{1}{|c|}{ Description } \\
\hline Sq & Root mean square height of the surface \\
Ssk & Skewness of height distribution \\
Sku & Kurtosis of height distribution \\
$\mathbf{S p}$ & Maximum height of peaks \\
$\mathbf{S v}$ & Maximum height of valleys \\
$\mathbf{S z}$ & Maximum height of the surface \\
$\mathbf{S a}$ & Arithmetic mean height of the surface \\
\hline
\end{tabular}


For sheen consideration, the most important values to consider are the skewness (Ssk) and the kurtosis (Sku) of the surface texture. These values represent the symmetry and deviation from an ideal bell curve of height distribution collected from all measured points. Ssk represents the degree of symmetry of the surface heights about the mean plane. The sign of the Ssk value indicates the predominance of peaks (Ssk >0) or valley structures $(\mathrm{Ssk}<0)$ on the surface of the film. Sku indicates the presence of exceedingly high peaks/low valleys $(\mathrm{Sku}>3.00)$ or the lack thereof $(\mathrm{Sku}<3.00)$ on the surface.

Therefore, a film surface with a normal distribution of heights (i.e. bell curve) will have a Ssk value of 0.00 and a Sku value of 3.00. A mainly flat film with several high, sharp peaks will have a slightly positive Ssk value and a large, positive Sku value. With that in mind, the Formula \#8 wet film has a slight predominance for peaks $(\mathrm{Ssk}=0.14)$ and those peaks are higher than what would be expected for a normal distribution of surface heights $(\mathrm{Sku}=3.58)$. After five minutes of drying, the paint has leveled resulting in a root mean square height of the surface that is smaller than that of the wet film. The Ssk and Sku both slightly increased, suggesting that there was a slightly greater predominance of peaks that developed during film formation and those peaks were sharper. The surface roughness of the film was virtually identical following another five minutes of drying. This suggests that the film's surface roughness is mainly developed within the first five minutes of drying, while the paint is leveling on the substrate. Results could vary depending on the mode of application and substrate on which the coating is applied. Formula \#8 applied to drywall with a roller could yield different surface roughness and film formation characteristics. 


\subsubsection{Commercial Paint Comparison}

Three interior flat commercial paints were obtained in order to make comparisons with Formula \#5 and \#8. One of them is being sold as a one coat paint and primer interior flat paint. The spread rate and relative light scattering values for the one coat product (Commercial 1) were collected and compared to Formula \#8 shown in Table 37:

Table 37: Data for Commercial 1 Comparison

\begin{tabular}{|c|c|c|c|c|c|c|c|}
\hline \multirow{2}{*}{ Paint } & \multirow{2}{*}{ KU } & \multirow{2}{*}{ ICI (P) } & \multirow{2}{*}{ Sheen } & $\begin{array}{c}\text { Spread Rate } \\
\left(\mathbf{f t}^{\mathbf{2}} / \mathbf{g a l}\right)\end{array}$ & \multicolumn{3}{|c|}{ Relative Light Scattering } \\
\cline { 6 - 8 } & & & & Wet & Dry & Oiled \\
\hline Commercial 1 & 100.3 & 1.496 & 4.5 & 407 & 100 & 100 & 100 \\
Formula \#8 & 100.1 & 1.154 & 2.7 & 543 & 83.2 & 171.6 & 80.2 \\
\hline
\end{tabular}

Although both Commercial 1 and Formula \#8 are both interior architectural flat latex paints, the analysis shows that they have significantly different properties. The spread rate of the commercial paint is well below that of Formula \#8. Air contribution is the driving factor behind the difference with Formula \#8 having almost twice as much hiding through air presence in the film. The lack of air in the commercial paint is due to the formulation being below the CPVC, which is the point at which the air void formation increases significantly. The commercial paint attempts to make up for the lack of air presence by introducing a greater amount of pigment into the formulation. The large pigment concentration is evident in the $17 \%$ higher relative light scattering of the wet film. Formula \#8 does have a lower sheen value, but the commercial paint is still considered flat.

The macroscope images of Formula \#5, Formula \#8, and the three commercial paints are shown in Figures \#17, 18, 19, 20, and 21, respectively: 


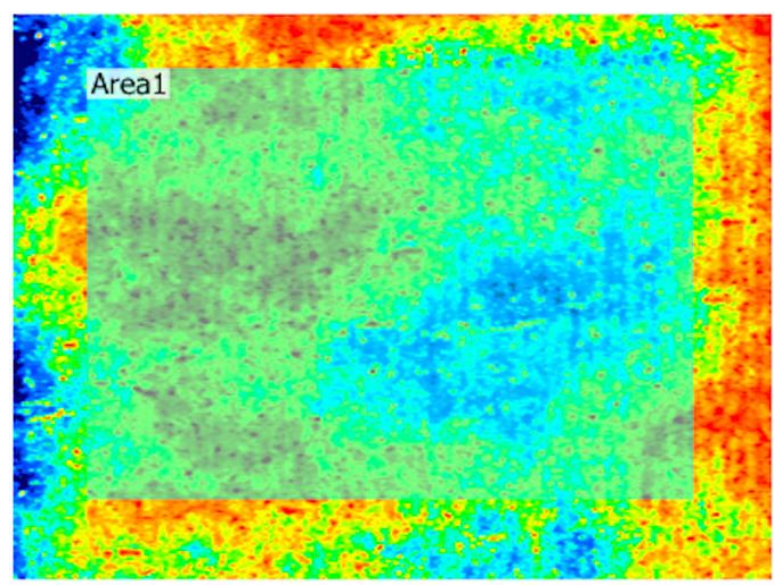

Figure 17: Formula \#5 dry film macroscope image.

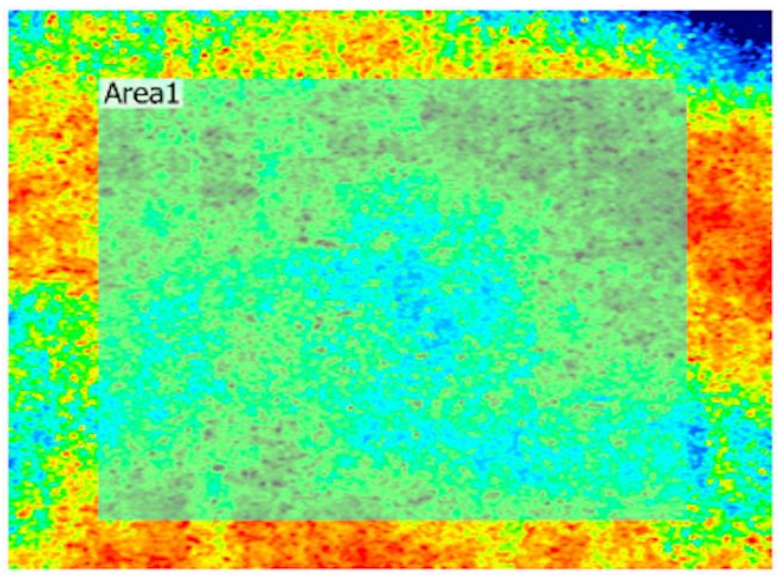

Figure 18: Formula \#8 dry film macroscope image.

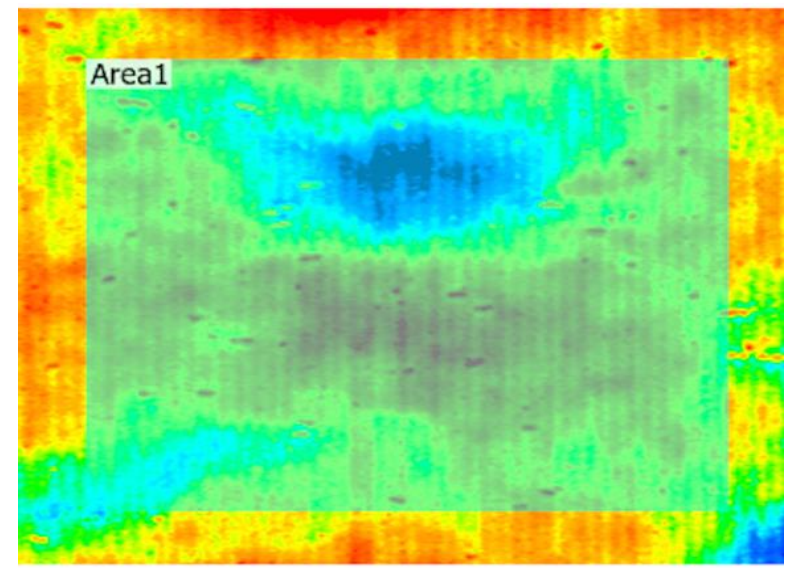

Figure 19: Commercial 1 dry film macroscope image. 


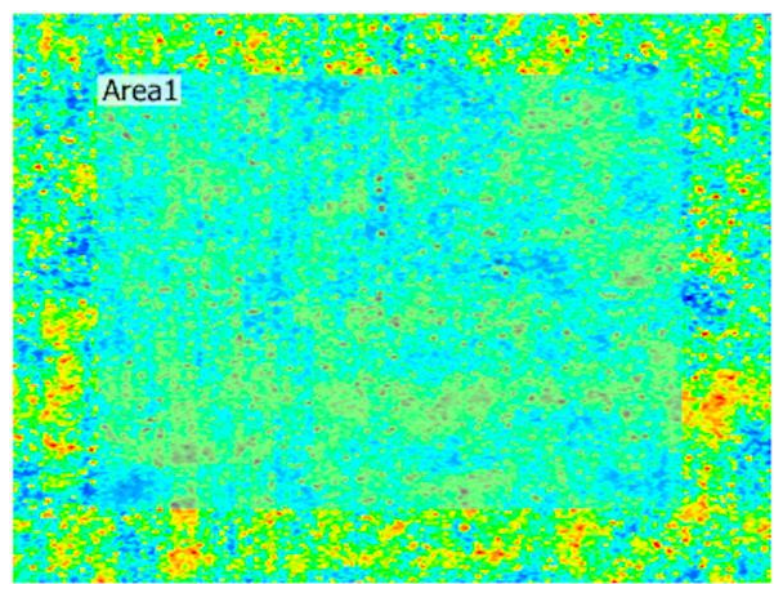

Figure 20: Commercial 2 dry film macroscope image.

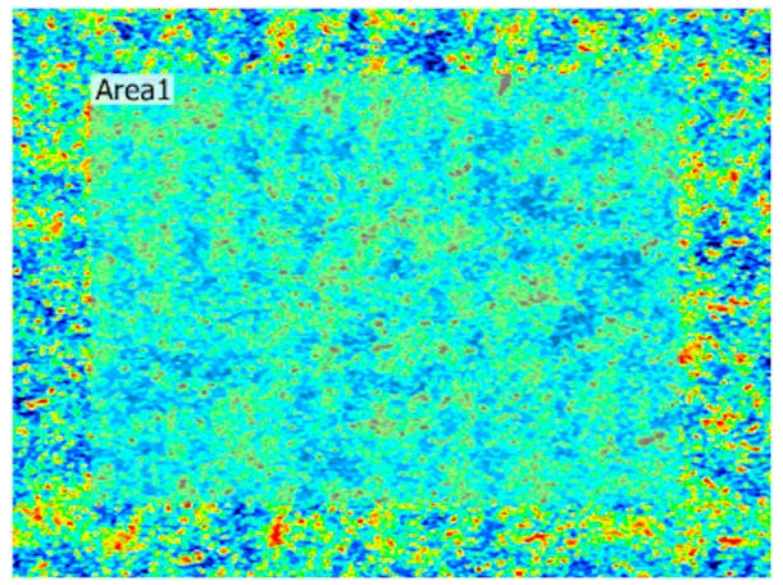

Figure 21: Commercial 3 dry film macroscope image.

Visually, Formula \#5 and Formula \#8 look very similar. This is not surprising because the paints are similar formulations, although they do have different sheen values. The three commercial paints each look unique. Quantification of the surface roughness of all the films was conducted by the Analyzer software and is presented in Table 38:

Table 38: Surface Roughness Data for Comparison

\begin{tabular}{|c|c|c|c|c|c|c|c|c|c|}
\hline Paint & Sheen & $\begin{array}{c}\text { Sq } \\
(\boldsymbol{\mu m})\end{array}$ & Ssk & Sku & $\begin{array}{c}\text { Sp } \\
(\boldsymbol{\mu m})\end{array}$ & $\begin{array}{c}\mathbf{S v} \\
(\boldsymbol{\mu m})\end{array}$ & $\begin{array}{c}\mathbf{S z} \\
(\boldsymbol{\mu m})\end{array}$ & $\begin{array}{c}\text { Sa } \\
(\boldsymbol{\mu m})\end{array}$ & $\begin{array}{c}\text { Area } \\
\left(\mathbf{c m}^{\mathbf{2}}\right)\end{array}$ \\
\hline Formula \#5 & 6.0 & 2.71 & -0.02 & 2.72 & 18.97 & 8.43 & 27.40 & 2.21 & 2.67 \\
Commercial 1 & 4.5 & 2.95 & -0.84 & 3.98 & 9.0 & 11.03 & 20.03 & 2.24 & 2.95 \\
Formula \#8 & 2.7 & 2.68 & 0.18 & 2.80 & 14.97 & 8.48 & 23.45 & 2.18 & 2.66 \\
Commercial 2 & 1.5 & 1.32 & 0.81 & 6.69 & 18.7 & 4.80 & 23.50 & 1.01 & 2.57 \\
Commercial 3 & 0.8 & 2.05 & 0.71 & 4.42 & 15.5 & 6.87 & 22.38 & 1.59 & 2.56 \\
\hline
\end{tabular}


Looking at the surface roughness values, we see that there is not a direct correlation between any of the surface roughness values that were collected and the sheen. However, there seems to be a slight increase in Ssk value with a decrease in sheen amongst the five paints tested for surface roughness. This suggests that there is a slight predominance of peaks in the films with low sheen values (e.g. Formula \#8, Commercial \#2, and Commercial \#3). On the other hand, a negative Ssk value for the paints with the higher sheen values (e.g. Formula \#5, and Commercial \#1) suggests a slight predominance of valleys on the film's surface. The high Sku values for the low sheen coatings suggest that they have sharper peaks relative to the higher sheen coatings. These observations are just general trends supported by the data, but there seems to be very little correlation between surface roughness and sheen value. For example, Formula \#8 has a sheen value of 2.7 and has almost identical surface roughness values as Formula \#5, which has a sheen value of 6.0. Formula \#8 achieves the project's goal of obtaining a sheen value of less than 5.0. However, Formula \#5 does not reach that standard, yet their surface roughness characteristics are virtually identical. Therefore, surface roughness values alone cannot predict sheen values. This must be true for at least this system.

\subsection{Future Work}

In the future, further spread rate procedure development will be needed in order to gain trustworthy results. Precise data was obtained through adapting the procedure to a shorter opacity chart. However, a large spread rate deviation was seen between the two drawdown vacuum plates described in the variability section of this paper. It still remains to be seen which of the two vacuum plates delivers more accurate spread rate values. 
Additionally, the physical properties of the formulations are going to have to be considered. Formulating above the CPVC allows for extraordinary hiding power due to air presence within the film as well as sheen reduction. However, the physical properties, such as scrub resistance, stain resistance, and washability tend to be sacrificed in this formulation space. Physical stability is the reason why the Commercial 1 paint is formulated below the CPVC. It creates a one coat, flat system without sacrificing its physical properties.

Formulating below the CPVC will not lead to the air void formation created when formulated above the critical pigment volume concentration. The use of hollow sphere particles is another method in which air voids can be incorporated into the dry paint film. Upon film formation, the water within the hollow sphere particles gets driven out of the void leaving behind an air-filled sphere. The difference in refractive index created by the air presence allows for improved hiding power in the same fashion as the above critical formulations. However, the below CPVC formulation will most likely have suitable physical characteristics for fundamental use, similar to Commercial 1. 


\section{CONCLUSION}

Although a one coat, flat latex formulation that delivered a spread rate of as high as $780 \mathrm{ft}^{2} / \mathrm{gal}$ was created, the sheen value was sacrificed. Acceptable sheen values, those below 5.0, were attained by removing pigment and replacing it with extender particles. Unfortunately, the spread rate decreased as a result of the formulation change. Formula \#8 created a sheen value of 2.7, which satisfies the projects's goal. However, the spread rate was only $545 \mathrm{ft}^{2} / \mathrm{gal}$, which does not reach the $600 \mathrm{ft}^{2} / \mathrm{gal}$ target coverage. Variations of Formula \#8 regarding its rheology modifier and dispersant package showed promise for reaching the desired values in future experiments. Overall, important progress was made with the work contained in this document, which will substantially help future one coat formulation development.

The spread rate procedure was adapted to deliver more precise results for high PVC paints. The new procedure includes a shorter opacity chart that dampens the shearthinning effect on spread rate determination in these formulations. Evolution of the spread rate procedure has the potential to make an impact on numerous projects outside of this one.

An attempt at correlating rheology with sheen development involved the creation of Formula \#8 variations with different associative thickener and dispersant chemistries. The relatively low latex concentration formulations were not greatly affected by the associative thickeners; therefore, they did not play a significant role in sheen development. The low shear rate rheology supported the conclusion that the thickener and dispersant chemistry is less than critical when it comes to sheen development. The 
extender package is the driving force that leads to sheen creation in these high PVC formulations.

A Keyence VR-3000 Series One-Shot 3D Measuring Macroscope proved that the sheen development takes place within the first five minutes when the high PVC formulations are drawn down an opacity chart. The macroscope also proved that there is not a direct correlation between the ISO 25178 surface roughness quantification values and sheen measurements. A slight trend was observed between the symmetry of the height distribution amongst higher versus lower sheen flat paints, but not all of the samples followed the trend. The macroscope data gave very similar surface roughness data for Formula \#5 and Formula \#8, but their sheen values are too different to support the idea that this surface roughness quantification technique can predict sheen values.

The formulation space of this one coat paint will have to be heavily considered in the future. Although physical properties were not tested, the above critical formulation is most likely lacking sufficient washability, stain, and scrub resistance. Formulating below the CPVC would combat physical imperfections. The addition of hollow sphere particles could aid in achieving high spread rates by introducing air into the dry paint film, similar to above critical paints. 


\section{REFERENCES}

(1) Fernando, R.H. "Polymeric Coatings Chem 444/544." Lecture Slides. (2014): 1545 .

(2) Graessley, W. The Entanglement Concept in Polymer Rheology. Berlin: SpringerVerlag, 1974.

(3) Koleske, J. V. Paint and Coating Testing Manual Fourteenth Edition of the Gardner-Sward Handbook. Philadelphia, PA: ASTM, 1995.

(4) Kroon, G., R. Reinartz, J. Laven, and R. Van Der Linde. "Interaction of Non-ionic (associative) Thickeners with the Continuous Phase of a Waterborne Paint." Progress in Organic Coatings 37 (1999): 199-201.

(5) Otsubo, Y. "Rheology Control of Suspensions by Soluble Polymers." Langmuir 11 (1995): 1893-898.

(6) Dziwok, K. "Thickeners for Viscosity Retention Upon Thickening." Paint \& Coatings Industry 2003.

(7) Horigome, M., and Y. Otsubo. "Long-Time Relaxation of Suspensions Flocculated by Associating Polymers." Langmuir 18 (2002): 1968-973.

(8) Van Den Haak, H., and L. Krutzer. "Design of Pigment Dispersants for High-solids Paint Systems." Progress in Organic Coatings 43 (2001): 56-63.

(9) Wicks, Z., F. Jones, S. Pappas, and D. Wicks. Organic Coatings: Science and Technology. 3rd ed. Hoboken, N.J.: Wiley-Interscience, 2007.

(10) Braun, J. Introduction to Pigments. Blue Bell, PA: Federation of Societies for Coatings Technology, 1993.

(11) Goldschmidt, A., and H. Streitberger. BASF Handbook on Basics of Coating Technology. 2., Rev. ed. Hannover, Germany: Vincentz Network, 2007.

(12) Brock, T., M. Groteklaes, and P. Mischke. European Coatings Handbook. Lamspringe, Germany: Quensen Druck, 2010.

(13) Diebold, M. "A Monte Carlo Determination of the Effectiveness of Nanoparticles as Spacers for Optimizing TiO2 Opacity." J. Coat Tech Res 8 (2011): 541-52. 
(14) Trezza, T., and J. Krochta. "Specular Reflection, Gloss, Roughness and Surface Heterogeneity of Biopolymer Coatings." J. Appl Polym Sci 79 (2001): 2221229.

(15) DuPont. "DuPont Ti-Pure Titanium Dioxide: Titanium Dioxide for Coatings." (2007): 5-22.

(16) Hanna, T. "Predicting Paint Properties from TiO2 Pigment Properties." J. Coat Tech Res 6 (2009): 26-31.

(17) Capelle, S., and S. Backer. "Specialised TiO2 Grade for Flat Paints." Polymers Paint Colour Journal (2015): 42-44.

(18) Thiele, E., and R. French. "Light-Scattering Properties of Representative, Morphological Rutile Titania Particles Studied Using a Finite-Element Method." Journal of the American Ceramic Society 81 (1998): 469-79.

(19) Winkler, J. Titanium Dioxide. Hannover: Vincentz Verlag, 2003.

(20) Braun, J., A. Baidins, and R. Marganski. "TiO2 Pigment Technology: A Review." Progress in Organic Coatings 20 (1992): 105-38.

(21) DuPont. "Effective Utilization of Titanium Dioxide." (2002): 1-7.

(22) Hergert, W. The Mie Theory Basics and Applications. Berlin: Springer, 2012. 


\section{APPENDIX A}

Pigment and Extender Particle Properties

\begin{tabular}{ccc}
\hline Material & $\begin{array}{c}\text { Oil Absorption } \\
(\mathbf{g} / \mathbf{1 0 0 g})\end{array}$ & $\begin{array}{c}\text { Mean Particle Size } \\
(\boldsymbol{\mu m})\end{array}$ \\
\hline Chemours® Flat Grade $\mathrm{TiO}_{2}$ & 45 & 0.53 \\
Chemours® Universal Grade $\mathrm{TiO}_{2}$ & 13.9 & 0.36 \\
Kaolin Clay & 15 & 1.3 \\
Kaolin Clay 2 & 120 & 0.7 \\
$\mathrm{CaCO}_{3}$ & 14 & 3.5 \\
Diatomaceous Earth & 120 & 12 \\
Diatomaceous Earth 2 & 135 & 13 \\
Alumina Silicate & 25 & 10.8 \\
Alumina Silicate 2 & 14 & 1.4 \\
\hline
\end{tabular}

Formulation \#1

\begin{tabular}{|c|c|}
\hline Material Name & Amount (\%) \\
\hline \multicolumn{2}{|c|}{ Grind } \\
\hline Water & $12-20$ \\
\hline Inorganic Dispersant & $0.1-0.3$ \\
\hline Dispersant A & $0.1-0.3$ \\
\hline Glycol & $0.5-2.0$ \\
\hline Coalescent Aid & $1-4$ \\
\hline Defoamer & $0.1-0.3$ \\
\hline 2\% Solution HEC A & $4-8$ \\
\hline Chemours $®$ Flat Grade $\mathrm{TiO}_{2}$ & $19-23$ \\
\hline Kaolin Clay & $4-6$ \\
\hline $\mathrm{CaCO}_{3}$ & $15-20$ \\
\hline Diatomaceous Earth & $1-4$ \\
\hline \multicolumn{2}{|c|}{ Letdown } \\
\hline $2 \%$ Solution HEC A & $12-17$ \\
\hline Latex A & $13-16$ \\
\hline Neutralizer & $0.1-0.3$ \\
\hline Water & $0.2-0.5$ \\
\hline HASE Thickener & $0.05-0.20$ \\
\hline
\end{tabular}


Formulation \#2

\begin{tabular}{|c|c|}
\hline Material Name & Amount (\%) \\
\hline Wrind \\
\hline Water & $12-20$ \\
Inorganic Dispersant & $0.1-0.3$ \\
Dispersant A & $0.1-0.3$ \\
Glycol & $0.5-2.0$ \\
Coalescent Aid & $1-4$ \\
Defoamer & $0.1-0.3$ \\
2\% Solution HEC B & $4-8$ \\
Chemours@ Flat Grade TiO ${ }_{2}$ & $19-23$ \\
Kaolin Clay & $4-6$ \\
CaCO & $15-20$ \\
Diatomaceous Earth & $1-4$ \\
\hline \multicolumn{2}{|c|}{ Letdown } \\
\hline 2\% Solution HEC B & $12-17$ \\
Latex A & $13-16$ \\
Neutralizer & $0.1-0.3$ \\
Water & $0.2-0.5$ \\
HASE Thickener & $0.05-0.20$ \\
\hline \%NVW - 52\%; \%NVV - 31\%; PVC - >60\%; TiO $2=2.3-3.1 \mathrm{lb} /$ gal \\
\hline
\end{tabular}


Formulation \#3

\begin{tabular}{|c|c|}
\hline Material Name & Amount (\%) \\
\hline \multicolumn{2}{|c|}{ Grind } \\
\hline Water & $12-20$ \\
\hline Inorganic Dispersant & $0.1-0.3$ \\
\hline Dispersant $\mathrm{C}$ & $0.1-0.3$ \\
\hline Glycol & $0.5-2.0$ \\
\hline Coalescent Aid & $1-4$ \\
\hline Defoamer & $0.1-0.3$ \\
\hline 2\% Solution HEC B & $4-8$ \\
\hline Chemours $®$ Flat Grade $\mathrm{TiO}_{2}$ & $19-23$ \\
\hline Kaolin Clay & $4-6$ \\
\hline $\mathrm{CaCO}_{3}$ & $15-20$ \\
\hline Diatomaceous Earth & $1-4$ \\
\hline \multicolumn{2}{|c|}{ Letdown } \\
\hline 2\% Solution HEC B & $12-17$ \\
\hline Latex A & $13-16$ \\
\hline Neutralizer & $0.1-0.3$ \\
\hline Water & $0.2-0.5$ \\
\hline HASE Thickener & $0.05-0.20$ \\
\hline
\end{tabular}


Formulation \#4

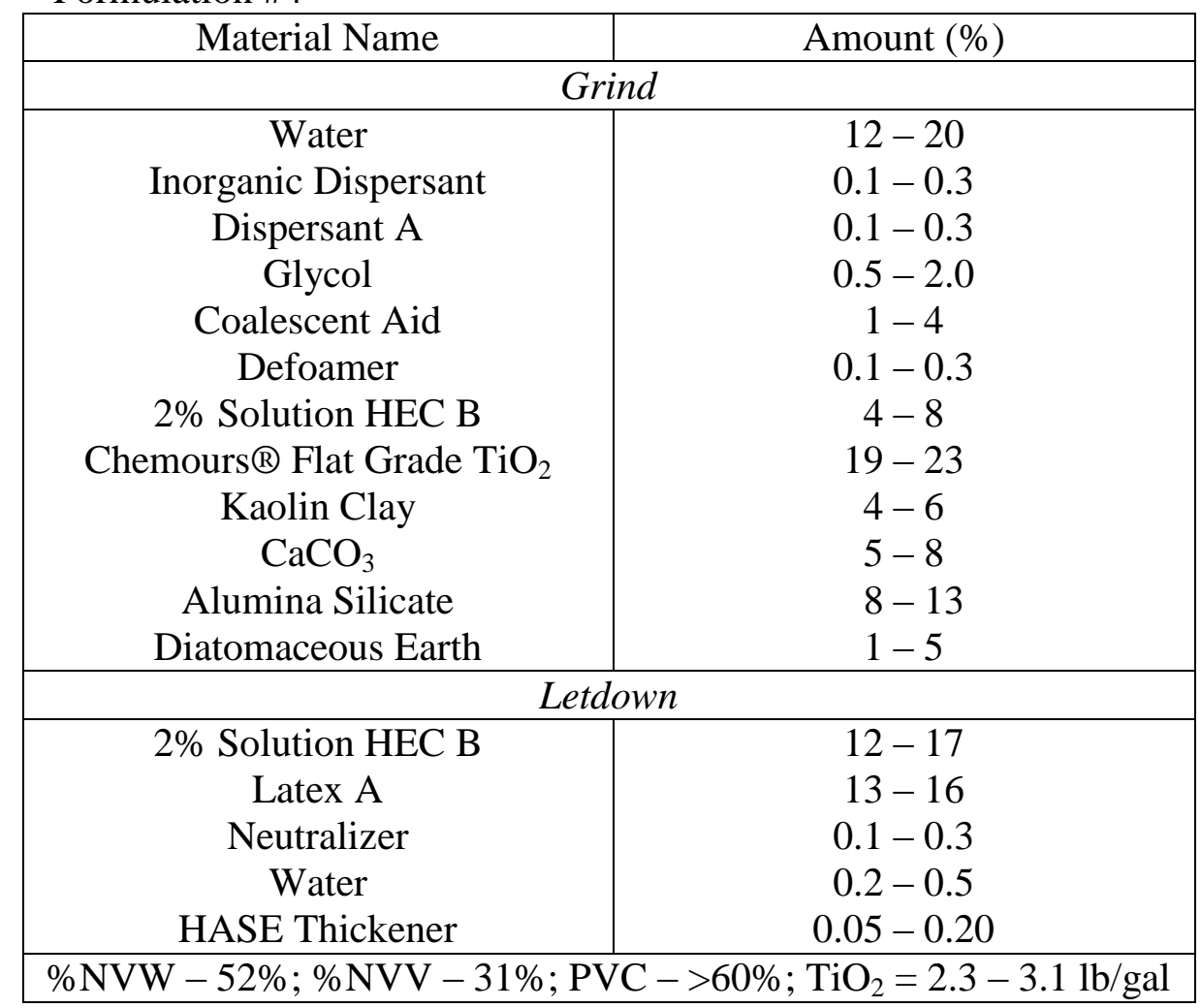


Formulation \#5

\begin{tabular}{|c|c|}
\hline Material Name & Amount (\%) \\
\hline \multicolumn{2}{|c|}{ Grind } \\
\hline Water & $12-20$ \\
\hline Inorganic Dispersant & $0.1-0.3$ \\
\hline Dispersant A & $0.1-0.3$ \\
\hline Glycol & $0.5-2.0$ \\
\hline Coalescent Aid & $1-4$ \\
\hline Defoamer & $0.1-0.3$ \\
\hline $2 \%$ Solution HEC B & $4-8$ \\
\hline Chemours $®$ Universal Grade $\mathrm{TiO}_{2}$ & $2-5$ \\
\hline Chemours® Flat Grade $\mathrm{TiO}_{2}$ & $19-23$ \\
\hline Kaolin Clay & $4-8$ \\
\hline $\mathrm{CaCO}_{3}$ & $2-6$ \\
\hline Alumina Silicate & $8-12$ \\
\hline Diatomaceous Earth & $1-4$ \\
\hline \multicolumn{2}{|c|}{ Letdown } \\
\hline 2\% Solution HEC B & $12-17$ \\
\hline Latex A & $13-16$ \\
\hline Neutralizer & $0.1-0.3$ \\
\hline Water & $0.2-0.5$ \\
\hline HASE Thickener & $0.05-0.20$ \\
\hline \multicolumn{2}{|c|}{$\% \mathrm{NVW}-54 \% ; \% \mathrm{NVV}-32 \% ; \mathrm{PVC}->60 \% ; \mathrm{TiO}_{2}=2.3-3.1 \mathrm{lb} / \mathrm{gal}$} \\
\hline
\end{tabular}


Formulation \#6

\begin{tabular}{|c|c|}
\hline Material Name & Amount (\%) \\
\hline Grind \\
\hline Water & $12-20$ \\
Inorganic Dispersant & $0.1-0.3$ \\
Dispersant A & $0.1-0.3$ \\
Glycol & $0.5-2.0$ \\
Coalescent Aid & $1-4$ \\
Defoamer & $0.1-0.3$ \\
2\% Solution HEC B & $4-8$ \\
Chemours® Universal Grade $\mathrm{TiO}_{2}$ & $2-6$ \\
Chemours ${ }_{2}$ Flat Grade $\mathrm{TiO}_{2}$ & $19-23$ \\
Kaolin Clay 2 & $4-8$ \\
CaCO & $2-6$ \\
Alumina Silicate & $8-12$ \\
Diatomaceous Earth & $1-4$ \\
\hline \multicolumn{2}{|c|}{ Letdown } \\
\hline 2\% Solution HEC B & $12-17$ \\
Latex A & $13-16$ \\
Neutralizer & $0.1-0.3$ \\
Water & $0.2-0.5$ \\
HASE Thickener & $0.05-0.20$ \\
\hline \%NVW - 54\%; \%NVV - 32\%; PVC - >60\%; $\mathrm{TiO}_{2}=2.3-3.1 \mathrm{lb} / \mathrm{gal}$ \\
\hline \multicolumn{2}{|c|}{} \\
\hline
\end{tabular}


Formulation \#7

\begin{tabular}{|c|c|}
\hline Material Name & Amount (\%) \\
\hline \multicolumn{2}{|c|}{ Grind } \\
\hline Water & $12-20$ \\
Inorganic Dispersant & $0.1-0.3$ \\
Dispersant A & $0.1-0.3$ \\
Glycol & $0.5-2.0$ \\
Coalescent Aid & $1-4$ \\
Defoamer & $0.1-0.3$ \\
2\% Solution HEC B & $4-8$ \\
Chemours@ Flat Grade TiO ${ }_{2}$ & $19-23$ \\
Kaolin Clay & $4-8$ \\
CaCO & $2-6$ \\
Alumina Silicate & $8-12$ \\
Diatomaceous Earth 2 & $1-4$ \\
\hline \multicolumn{2}{|c|}{ Letdown } \\
\hline 2\% Solution HEC B & $12-17$ \\
Latex A & $13-16$ \\
Neutralizer & $0.1-0.3$ \\
Water & $0.2-0.5$ \\
HASE Thickener & $0.05-0.20$ \\
\hline \%NVW - 53\%; \%NVV - 31\%; PVC - >60\%; TiO $2=2.3-3.1 \mathrm{lb} / \mathrm{gal}$ \\
\hline
\end{tabular}


Formulation \#8

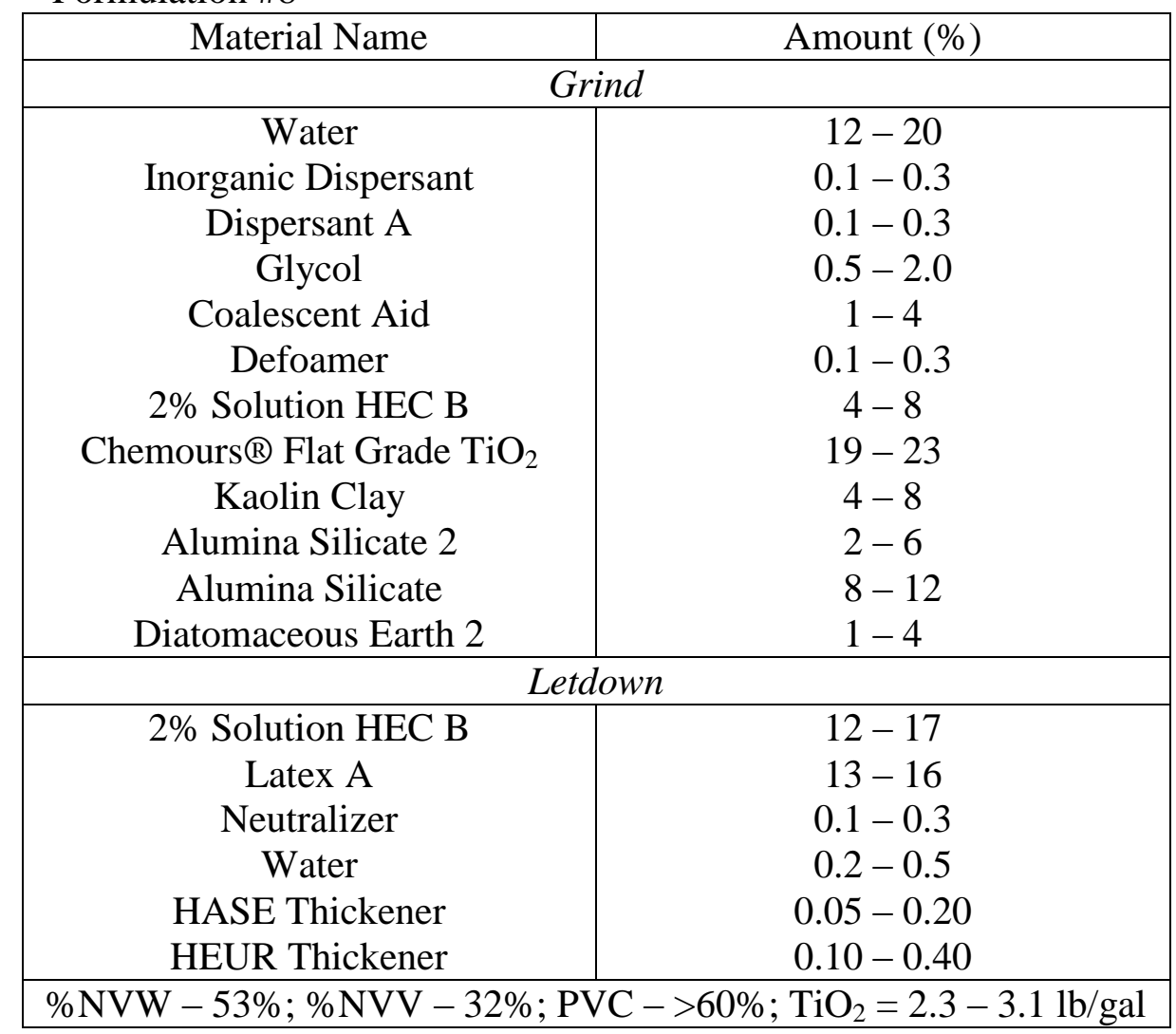

